\title{
Families of Roles: A new theory of occurrent-dependent roles
}

\author{
Riichiro Mizoguchi ${ }^{\text {a }}$ Antony Galton ${ }^{\mathrm{b}}$ Yoshinobu Kitamura ${ }^{\mathrm{c}}$ Kouji Kozaki ${ }^{\mathrm{d}}$ \\ ${ }^{a}$ Research Center of Service Science, Japan Advanced Institute of Science and Technology, \\ mizo@jaist.ac.jp \\ ${ }^{\mathrm{b}}$ College of Engineering, Mathematics, and Physical Sciences, University of Exeter, UK, \\ apgalton@ex.ac.uk \\ ${ }^{\mathrm{c}}$ College of Information Science and Engineering, Ritsumeikan University, Japan, \\ y-kita@fc.ritsumei.ac.jp \\ ${ }^{\mathrm{d}}$ Institute of Scientific and Industrial Research, Osaka University, Japan, \\ kozaki@ei.sanken.osaka-u.ac.jp
}

\begin{abstract}
Roles are important both theoretically and practically for modelling the world around us. Although many theories of roles have been proposed, there remain aspects which are little understood. In this paper we investigate roles and their contexts from a temporal point of view. We introduce the idea of a family of occurrent-dependent roles as a means to organise prospective and retrospective derived roles around an original role from which they are derived. By this means we account for the existence of groups of similar roles which are difficult to distinguish without a careful analysis of the temporal aspects. Following detailed informal discussion, we present a preliminary formalisation of the key concepts and relations.
\end{abstract}

Keywords: theory of roles, classification of roles, derived role

\section{Introduction}

There are many kinds of roles, and they can be classified in various ways. One way is to classify a role according to the type of entity that can play it: some roles, such as teacher, speaker and front-wheel are played by objects and may therefore be called 'object roles'; others, such as preparation and post-process are played by occurrents (for example the particular activities that constitute a preparation for something else) and are therefore 'occurrent roles'. In this paper we will mainly discuss object roles. Another way to classify a role is in terms of the context it depends on: we will argue that roles such as schoolteacher and wife depend on contexts which are objects (in these examples a school and a marriage partnership respectively), and we therefore call roles of this kind 'object-dependent'; other roles depend on a context consisting of some process or event, as for example the context for speaker is an act of speaking, and these are therefore 'occurrent-dependent' roles. Roles that have been discussed in the literature are mainly object-dependent roles such as teacher, president, and wife; occurrent-dependent roles, by contrast, have been much less studied, and the purpose of this paper is to begin filling this gap.

In this paper, ${ }^{1}$ we investigate the important part played by time in the characterisation of certain occurrent-dependent roles such as candidate and murderer. We propose a new view of roles by which we distinguish between 'original roles' and 'derived roles', and introduce the new concept of a 'role family' which brings together an original role and its associated derived roles. What we ordinarily understand by the murderer role has a retrospective character in that it is defined in relation to some past event: a murderer is someone who has murdered someone in the past. Thus the role (murderer) can exist even at

\footnotetext{
${ }^{1}$ This paper extends ideas previously introduced in (Mizoguchi, Sunagawa, Kozaki, \& Kitamura,2007;Mizoguchi, Kozaki, \& Kitamura,2012b,2012a;Kozaki, Kitamura, \& Mizoguchi,2012). In developing these ideas further, we have found it convenient to make extensive revisions to some of the terminology. Where appropriate in what follows we will draw attention to significant deviations from the earlier usages.
} 
a time when its context (the murder event) is no longer present. When the murder is actually committed, the perpetrator is playing the role of murderer in a more direct sense, since the context for the role is then present (thus the role is ongoing). We call this more direct sense an original role, and the retrospective sense a derived role. This will be explained more fully below.

The plan of this paper is as follows. In $\$ 2$ we introduce the background theory of roles underpinning the work presented here: this develops work previously presented in (Mizoguchi et al.,2007). The roles discussed in this section are all object-dependent roles. In $\$ 3$ we turn our attention to occurrent-dependent roles, taking account of the division of occurrents into processes or events, and introduce the distinction between original and derived roles, leading to the idea of a family of roles, comprising an original occurrent-dependent role together with the derived roles arising from it. This is the central contribution of this paper. We conclude this section with an illustrative case study to help fix the various distinctions in the reader's mind. In $\$ 4$ we probe more deeply into some of the subtleties of the theory, paying close attention to the notion of the 'content' of a role; here we distinguish between 'definitional' and 'performable' contents, a distinction which leads in turn to a closer analysis of the notion of 'playing' a role, which we now divide into two distinct components called 'holding' and 'performing'. We explore the theory further in $\S 5$ by examining in detail a number of problematic cases requiring sensitive analysis. Then, in $\S 6$ we present a preliminary formalisation of our theory in first-order logic. A brief comparison with related work in presented in $\S 7$, and $\S 8$ concludes with some pointers to outstanding problems requiring further research.

\section{A theory of object-dependent roles}

A wheel is just a wheel, but the front wheel of a bicycle, while it is indeed a wheel, is not just a wheel: it is the front wheel of a bicycle. If the front wheel is removed from the bicycle and a new one put in its place, then the old front wheel is still a wheel but it is no longer the front wheel of the bicycle. Instead, a different wheel plays that role. Suppose the front wheel is removed and not replaced. The bicycle now has a missing front wheel - which is to say that it does not have a front wheel, but it has a place where a front wheel should be. In this section we introduce the terminology for describing situations like this in ontological terms.

\subsection{Roles, Role-holders, and Contexts}

We begin by clarifying the key terms we will need for our discussion of roles. We introduce these terms in the context of the bicycle example, but then go on to discuss them more generally and in relation to other examples.

- The bicycle itself, as a complex object, is the context for various roles, including the role front-wheel.

- The front-wheel role may be played by any suitable wheel, which may be called a potential player of the role, and when that happens, the wheel becomes a role-holder, the holder of the front-wheel role for that particular bicycle.

- A holder of the front-wheel role in a bicycle is contingently a part of the bicycle; there is a double contingency here, since:

1. a given wheel may at different times play the front-wheel role with respect to different bicycles (that is, it may play different instances of the generic front-wheel role), and it may at other times not play a front-wheel role at all;

2. the front-wheel role of a given bicycle may be played by different wheels at different times, and it may at other times not be played by any wheel at all; these are the times at which the bicycle has a missing front wheel: the front-wheel role still exists, but it is unplayed because there is no role-holder for it. 
All of these concepts - context, role, role-holder, player — and the relations amongt them may be thought of both at the class level, as universals, and at the instance level, as particulars (cf. Loebe,2005). Thus the generic front-wheel role is dependent on the generic context bicycle, while particular instances of the front-wheel role depend on particular instances of the context bicycle. This is illustrated in Figure 1, where we note that a particular instance Bicycle 39 of the class bicycle serves as a context for a particular role front-wheel-of-bicycle39, which is currently being played by the instance Wheel46 of the class wheel. The role front-wheel-of-Bicycle39 is itself an instance of the role class front-wheel-of-bicycle. The potential players of this role are wheels, that is, instances of the universal wheel; not every such instance is suitable to play this role, since any particular bicycle imposes restrictions on what kind of wheel can play its front-wheel role (for example, it needs to be a bicycle wheel of a particular size).

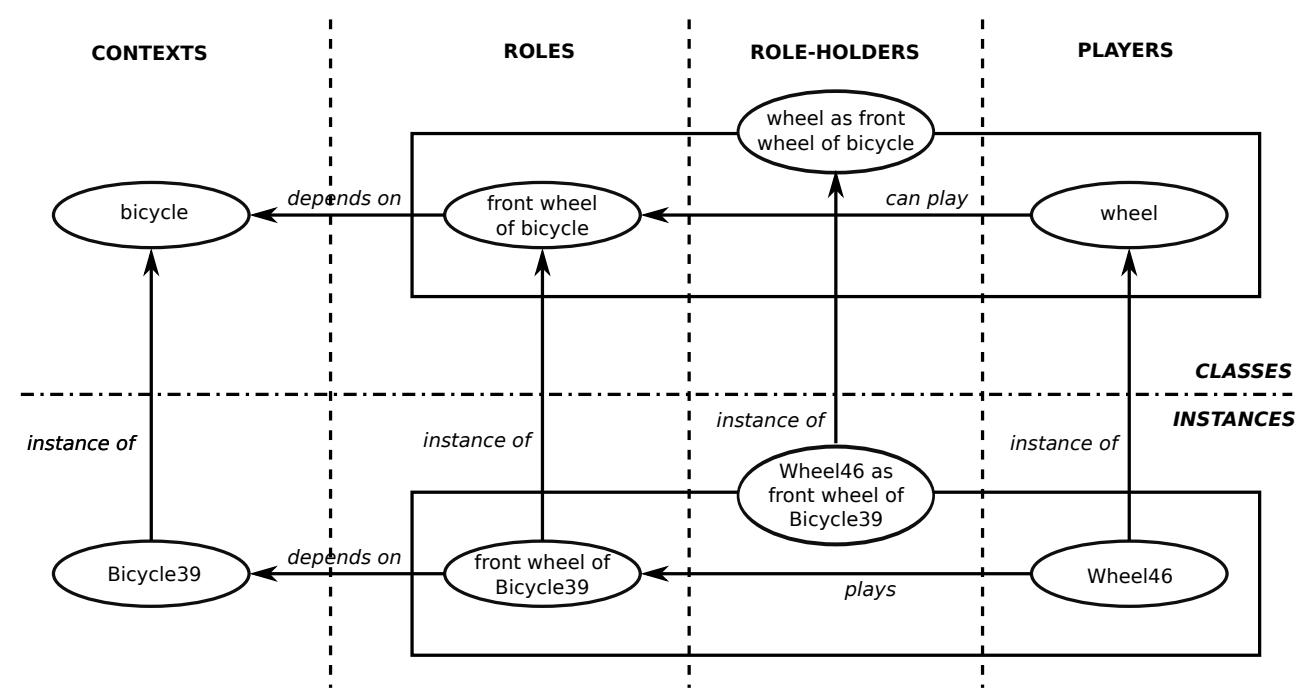

Fig. 1. The 'front wheel' role of a bicycle. Compare Figure 3 in (Loebe,2005) which, while similar, does not distinguish between roles and role-holders.

We describe the individual role-holder here as Wheel46-as-front-wheel-of-Bicycle39; it is neither a role nor simply a wheel as such, but a kind of composite of the two, a wheel qua player of the role. This composition can be interpreted as the addition of the properties of the role to the player. By playing the role, the role-holder inherits new properties from the role. We might describe a particular front wheel as incorrectly positioned, or loose, or the wrong size, and none of these qualities belong to the wheel as such, but only in its capacity as the player of the front-wheel role: they are, in other words, properties of the role-holder.

For clarity of exposition, we have chosen to introduce our view of roles in relation to a particularly simple example, but the theory of roles only really comes into it own when we turn to more complex examples, most notably those in which the players of roles are human beings or other animate subjects. In fact our diagram in Figure 1 is based on a diagram we have presented elsewhere (Mizoguchi et al.,2007) which treats the same complex of concepts and relations in the context of the schoolteacher role in a school.

In many ways the case of schoolteacher is analogous to front-wheel. ${ }^{2}$ A school provides the context for many different roles, not only various teachers, but also a head, pupils, secretaries, cleaners, and so on. These roles can be thought of as slots which are filled by the people who play the roles (compare "the place where a front wheel should be'). When $X$ plays a role $Y$, it means that X "acts as" $Y$, contingently acting in ways that characterise the role Y. If John plays a teacher role then John acts as a teacher, but can also then be said to be a teacher. This means that the word 'teacher' can be regarded as somewhat

\footnotetext{
${ }^{2}$ For brevity, we shall usually use teacher to designate this role; it is to be understood that, for the purposes of this paper, teacher refers to a schoolteacher, not, for example, a private teacher not attached to any educational establishment.
} 
ambiguous, referring now to the role itself and now to the role-holder, the person considered as a player of the role. Such entities have elsewhere been called 'qua individuals' (Masolo, Guizzardi, Vieu, Bottazzi, \& Ferrario,2005) or 'relational tropes' (Guizzardi,2005,2006).

More generally, if a collection of entities are interrelated in such a way that it is natural to consider them as forming a unitary whole, then this whole may be regarded as a context within which each of the entities it comprises plays a role. Thus an entity can be seen as a role-holder with respect to a role defined within a context. The role-holder is dependent on both the entity itself and the role, and the role is dependent on the context. If the context is destroyed then the role disappears and therefore the entity ceases to be a role-holder: in effect the role-holder also disappears, just leaving the entity. Thus if a school is closed down, the teachers still exist as people but no longer as teachers (in that school — of course they may get jobs in other schools, playing different but analogous roles in the new contexts); similarly, if a bicycle is dismantled, its front wheel still exists as a wheel but no longer as a front wheel — but again, it may be redeployed as the front wheel of a different bicycle, playing another instance of the front-wheel role.

By a potential player of a role we mean an entity that is able to play that role. Thus any person with appropriate qualifications is a potential player of the teacher role; a person who plays it is thereby a teacher role-holder. In many cases, potential players are of natural types such as human, but a roleholder can also be a potential player of another role: in a school, for instance, the potential players of the head-of-year-9 role are themselves already role-holders, players of the teacher role.

\subsection{Roles and role-holders}

In the previous section we noted that words such as 'teacher' can display an element of ambiguity, referring either to a role or a role-holder. In fact this potential ambiguity is compounded by the fact that a number of properties can be said to apply to both roles and role-holders: for example, both the role and the role-holder are ontologically dependent on their context. In view of this, the reader may wonder why it is necessary to distinguish between a role and its holder. We offer two main reasons for this, as follows.

First, a role-holder has all the properties of the individual playing the role, as well as additional properties which result from the fact that they are playing the role. Thus a teacher, being a person, has a name, address, date of birth, height, eye-colour, marital status, and so on, none of which is derived from the teacher role, but also has properties such as being in charge of a certain class, or being a member of a particular department in the school, which are only possessed by the individual as a player of the teacher role. A role, on the other hand, does not have any of the properties of an individual; for example, it does not make sense to associate an eye-colour with a teacher role.

Second, a role can exist even in the absence of a corresponding role-holder. If a school has a vacancy for a teaching position then the role exists, ready to be played, but until someone is actually appointed to the position there is no role-holder for it. Therefore the role and the role-holder must be distinct entities. The bicycle with a missing front wheel is a similar case where a role exists without a role-holder.

This view of roles and role-holders is not shared by the majority of ontologists. Steimann (2000) lists 15 "features" of roles which he has identified as having been put forward in the literature on roles; the features are not all compatible, and indeed his features 14 and 15 are that an object and its roles share identity and that an object and its roles have different identities respectively, the latter view being regarded as "quite singular". In fact, we find we can give qualified agreement to both 14 and 15, so long as 'role' is understood as 'role-holder' in the former and as 'role' in the latter. More exactly, when an object plays a role, the role-holder which thereby exists is related to the object rather as the vase is related to the clay it is made of: this relation is often characterised as one of constitution rather than identity; that is, the vase is constituted by the clay, meaning that while in a certain sense the vase "is" the clay, it cannot simply be equated with it since the two have distinct identity criteria (for example the clay continues to exist after the vase is destroyed). In a similar way, we might say that a teacher "is" a person, but this cannot be strict identity since the person already existed before becoming a teacher, and when the person resigns from the role then the teacher no longer exists but the person still does. Hence our assent to Steimann's 14 is only qualified. This also shows that the role is distinct from both the object and the role-holder: the teacher role 
that the person played may continue to exist after the person has resigned from it, perhaps to be filled by a different person.

\subsection{Determining context}

In the examples given above, we have taken the view that a role-holder is part of the context of its role. The front wheel of a bicycle is part of the bicycle, and the bicycle is the context for the front-wheel role; a schoolteacher is part of a school, and the school is the context for the schoolteacher role. In these cases we are dealing with roles whose contexts are objects, and we therefore refer to such roles as objectdependent roles. By 'object' here we mean an independent continuant; thus object-dependent roles are also continuant-dependent roles. The main focus in the remainder of this paper, however, will be on a different class of roles, which we call occurrent-dependent. These will be introduced in section 3. Before we proceed to these, however, we must provide further justification for considering the contexts of some roles to be objects.

We stated above that the context for a schoolteacher role is the school in which the role is held. The teacher, qua role-player, is an employee of the school, contracted to perform certain duties such as teaching. This might suggest alternative possibilities for identifying the context of the role. Might not the context be the state of having been appointed by the school to teach? Or perhaps it is the activities, such as teaching, that are performed by the teacher in discharge of the duties laid down in the contract? The latter would make schoolteacher an occurrent-dependent role; the former would make it a state-dependent role, though whether one regarded this as continuant-dependent or occurrent-dependent would depend on whether one sided with BFO (which treats states as continuants) or with DOLCE (which treats them as occurrents).

A problem with both these possibilities - context as state, and context as activity - is that they fail to account for some situations in which it is natural to refer to a schoolteacher role. A schoolteacher is still a schoolteacher when asleep or on holiday, and therefore not performing any of the activities associated with the role. This shows that those activities cannot be the context - or at any rate not the whole of the context - for the role. Moreover, as already noted, if a school has a vacancy for a teacher, this vacancy may be considered as defining a teacher role which is unfilled: the context of this role cannot be a state of employment, since currently no-one is in that state, nor can it be any actually occurring activities performed by a holder of the role, since currently there are none. Thus the role cannot be dependent either on the state of employment of someone playing the role or on any activities which might be performed by such a player, since the role can exist in the absence of any of these things. But the role cannot exist in the absence of the school itself: if the school were to be shut down then all its associated roles would cease to exist. Thus the role is ontologically dependent on the school, which may therefore be identified as the context of the role.

Similar considerations apply to other roles we mentioned above as being object-dependent, such as president and wife. In a republic, the role of president is laid down in the constitution which defines the republic as a political entity. Typically, the person who holds that role, the president himself or herself, has been elected (not necessarily democratically!) to that position, and in playing the role will typically undertake various duties that are laid down in the constitution. But neither the state of having been elected as president, nor the activities involved in discharging the presidential duties, can provide the context for the role, since the role itself can exist in their absence. When Kennedy was assassinated, for example, vice-president Johnson automatically assumed the role of president despite not having been elected to that position; and if the president were to undergo a prolonged period of illness, the characteristic presidential activities might fail to be performed, without the role thereby ceasing to exist. In fact the role of president is defined in relation to the republic via its constitution, and not to the state of having been elected, which merely describes the normal way in which someone comes to hold the role, nor to the actual performance of certain duties, which again do not determine the existence of the role even though under normal conditions they are strongly associated with it. 
The role wife may be defined as one component of a marriage partnership; a specific instance such as John's wife could be defined as 'the female member of a marriage partnership in which the other member is John'. Such a partnership — which is an object — comes into being as a result of a marriage ceremony; and if one is a member of a marriage partnership then one is, of course, in the state of being married, but it seems to us more natural to say that the state of being married is dependent on the partnership than the other way round. This being so, it must be the partnership, and not the state dependent on it, that forms a context for its constituent roles of husband and wife. The issue is however less clear-cut than in the case of schoolteacher, since a marriage partnership can only exist if both its constituent roles are filled: if John is unmarried there is no unplayed role John's wife, since this would imply that John was part of a marriage partnership in which one of the roles is vacant. But such partnerships do not exist!

\section{Occurrent-dependent roles}

\subsection{Processes and process-dependent roles}

In common with many other researchers (compare Moens \& Steedman,1988), we regard process as a broad category of occurrent entities characterised in terms of the manner in which they occupy time. Processes, in contrast to events, are open-ended, meaning that when a process is in operation, there is no reason, in principle, why it should not continue in operation indefinitely. A process does not have a natural termination point at which it may be said to become complete; instead, when a process stops operating, it just ceases, with no notion of completion or finality associated with it. Thus, for example, singing, running, and eating are all processes, whereas singing a song, running a mile, and eating an apple are events. ${ }^{3}$ From this it is evident that at least some events are so to speak "made" of processes: the singing of a song, which is an event, comprises an instance of the singing process that constitutes a completed performance of a song.

The examples given so far are all human activities, and such activities form one important subclass of processes. But there are also many processes which are not the activities of humans or other animals, notably natural processes such as the flowing of a river, the falling of the rain, the growth of a plant, and the circulation of the blood. We shall, however, have less to say about these kinds of processes, although they too can have roles associated with them.

A large class of roles may be characterised in terms of participation in a process. This is most obvious in cases where the process is an activity, by which we mean a process which is performed or enacted by some agent, who thereby is said to participate in the process. This gives us roles such as singer, runner, and eater. We will see below that with terms such as these there are often delicate issues of interpretation, depending on the context in which they are used, but for now we focus on what may be called pure process-dependent roles, defined as follows:

- For an activity $X$ ing, an agent $x$ plays the role of $X$ er at precisely those times at which $x$ is $X$ ing.

In this sense, one is an eater/runner/singer just when one is actually eating/running/singing.

It should be noted, however, that it is not always clear exactly when any of these activities is actually in progress. Take singing, for example. This can be interpreted narrowly or broadly. In the narrowest sense of the word, one is only singing when one is actually producing musical sounds with the voice. In the course of singing a song, there may be several bars of rest during which one is not actually singing in this narrow sense; but there is a somewhat broader sense in which it is natural to say that one is singing even during such rests. Now, consider the case of someone who says 'I have been singing all evening', having spent the evening performing in a vocal concert. During the concert there will undoubtedly have been times when she was not singing in either of the two preceding senses, for example while the audience were applauding, in the gaps between consecutive items in the concert, and during the interval. But in a

\footnotetext{
${ }^{3}$ More exactly, these expressions designate event types, of which there may be many concrete instances, or tokens.
} 
broader sense still, it may be said that she was singing throughout those times as well. Thus the process of singing may be conceived in various different ways, to each of which corresponds, therefore, a different understanding of the role singer.

It is sometimes said that processes can admit "gaps", and examples like the foregoing are cited in support of this. We believe that this is a misunderstanding: in fact we regard processes as dissective in nature, meaning that if a process is in operation over some interval of time then it is in operation over all subintervals of that interval. This is certainly the case for each of the three interpretations of singing described in the previous paragraph; if we call these singing ${ }_{1}$, singing 2 , and singing ${ }_{3}$, respectively, then

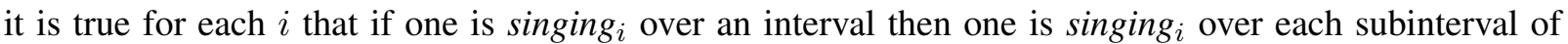
that interval. When people say that processes admit gaps, their purported justification for this amounts to saying that if one is singing 2 or singing 3 over an interval then there may be subintervals of that interval

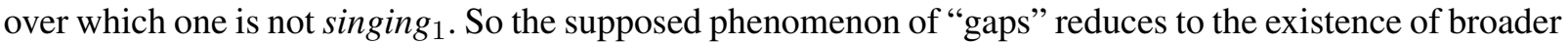
and narrower perspectives on an activity.

The dissectivity of a process, when taken to the limit, suggests that when a process is in operation over an interval, it can be said to be in operation at each instant of that interval: 'What were you doing at exactly $12 \mathrm{o}$ 'clock today?' - 'I was singing'. It is no objection to this that any singing must in fact extend over an interval: the fact that one cannot be singing only at 12 o'clock does not imply that one cannot be singing at 12 o'clock. This leads further to the idea that a process may possess different properties at different instants (progressing at different rates, for example, or with different intensities, or in different locations), which means that a process, unlike an event, may be said to undergo change. In this respect, processes have a continuant-like character, as argued in (Galton \& Mizoguchi,2009); but they are also occurrent-like, in that as mentioned above they provide the "raw material" for events, and in this paper we treat process-dependent roles as a subclass of occurrent-dependent ones.

In the discussion of the different granularities with respect to which a process-dependent role such as singer might be defined, we came close to trespassing on the "delicate issues" mentioned in the third paragraph of this section. If we ask how many singers there are in a certain choir, one possibility might be to interpret singer here as a process-dependent role in which the process is interpreted so broadly that one may be 'singing in the choir' even on days when there is no rehearsal or performance. This does seem rather strained, however, and we regard it as more natural to treat 'singer' here as denoting the object-dependent role choir-member, whose context is the choir, and not a process-dependent one.

\subsection{Events and event-dependent roles}

As suggested in the previous section, a key distinction between events and processes is that an event, unlike a process, carries with it the notion of an intrinsic completion. This means that once an event has occurred, it cannot in any sense go on occurring; at best, there might be an occurrence of another event of the same type. Once you have sung a song, you can sing it again, but that is a new event, not a continuation of the preceding one.

Events may be durative (extended in time) or punctual (effectively or really instantaneous), and to some extent this is a matter of granularity; when a train starts moving, for example, this is naturally regarded as instantaneous, but if we step up the temporal magnification we can see that it takes some time for the motion to be communicated from the engine to all the parts of the train, so the inception of motion is "smeared out" over an interval, at the beginning of which all parts of the train are at rest and at the end of which all the parts are in motion. Thus an event which is punctual at a coarse granularity may become durative at a finer one.

For our purposes, it is convenient to follow the analysis of Moens and Steedman (1988), whose discussion of events makes use of a fundamental tripartite structure called a nucleus, consisting of a punctual culmination, an associated preparatory process, and a consequent state. One can view the same situation at different granularities to yield different nuclei. An example considered by Moens and Steedman is climbing Everest. On a close view, we can take the final attainment of the summit to be the culmination, with the climbing that leads up to this as the preparatory process, and the state of being at the top 
the consequent state. On a broader view, we can take the whole 'culminated process' consisting of the climbing together with the attainment of the summit to be the culmination, in which case the preparatory process consists of activities leading up to the climbing, such as assembling the necessary equipment and travelling to base camp; the consequent state is that of having climbed Everest - a state which persists even after the descent.

What roles are associated with events? Since climbing is a process, there is of course a pure processdependent role climber, which as described previously may be interpreted more or less narrowly. But here it is not just climbing that is under consideration, it is climbing Everest. This suggests a role Everest-climber. When can someone be said to play this role? In (Masolo, Vieu, Kitamura, Kozaki, \& Mizoguchi,2011), definition d19 states that $x$ is an Everest climber at time $t$ if and only if $x$ is at $t$ the agent of a climbing $e$ of which the goal is the top of Everest. This appears to leave it open whether the goal of $e$ has to be achieved in order for the agent to be an Everest-climber. But if one starts climbing up Everest with the intention of reaching the top, and gives up before getting there, then it does not seem appropriate to say that one is an Everest-climber. In fact, it is only at the moment of reaching the top that once can truly proclaim 'Now I am an Everest-climber!'. So it does seem that the role Everest-climber is only played by those who complete an ascent of Everest, and the time at which this role is played is, precisely, the moment of completion. If you do not make it to the top, you are a failed Everest-climber, which is a quite different role.

Having reached the summit, and thus become an Everest-climber, there is then a further sense in which one can be said to remain an Everest-climber. In this sense of the term, an Everest-climber is not just someone in the act of reaching the summit of Everest, but more generally someone who has this achievement to their credit, meaning that they have reached the summit in the past. In this latter sense, it is a role one retains for the rest of one's life, and perhaps even beyond. Roles such as Oscar-winner and murderer are similar in this respect. In (Masolo et al.,2011) this kind of role is called a 'historical role', and the most important thing to note about such roles is that a person can only play one of them by virtue of having previously played the more immediate role from which it is derived. Thus you can be an Everest-climber in the historical sense only if you have previously been an Everest-climber in what we might call the "experiential" sense: at some past time $t$ you attained the summit of Everest.

It often happens that the words used to denote event-dependent roles are systematically ambiguous in this way. We shall use the following terminology to describe event-dependent roles of the kind we have discussed here:

- An original event-dependent role is played by a participant of an event at the time that event culminates; the culmination of the event is then the context for the role.

- A retrospective derived event-dependent role (or retrospective role for short) is played by a participant of an event at any time during which the consequent state associated with the event holds. The context of the role is again the culmination of the event.

Another example is witness. A person plays the original witness role when they actually see the event to which they are witness. After the event is over, they are no longer witnesses in this sense, but they are still witnesses to the event, and might for example be interviewed by the police or summoned to court in precisely that capacity; but this witness role is a derived role - you cannot be a witness in this sense without first being a witness in the original sense. ${ }^{4}$ As discussed above, a similar distinction exists for the role murderer — and also, we might add, victim.

It will be noticed that both an original event-dependent role and the retrospective role derived from it depend on the same context. The difference is that in the case of an original role, the context is present at the time the role is being played, whereas with a derived role this is not the case, or not necessarily so. In this connection we now state explicitly how we will use the terms 'exist' and 'present' in this paper. We use the word 'exist' in a timeless sense that applies to any fully determinate particular located in space and time, whereas we only apply the word 'present' to those existent particulars whose time of existence

\footnotetext{
${ }^{4}$ For more on witness, see $§ 5.2$.
} 
includes the present. Thus in the case of the retrospective Everest-climber role the context, which is the actual attainment of the summit, still exists but is no longer present.

There may of course be some uncertainty as to exactly when an original role is played: if a man puts poison into his victim's drink, he does not thereby become a murderer until the drink is consumed and the victim dies, which may be some time afterwards (by which time it is possible that the murderer himself is dead). When did the murder take place: when the poison was laid or when the victim died? There is a good deal of discussion on this matter in the philosophical literature on action and responsibility (see Davidson,1969;Thomson,1971;Pols,2013 amongst many others); but this does not vitiate our concept of original role since any uncertainty attaching to this in particular cases is already present in the scenario to which the concept is being applied.

One possible approach to this is to say that the context for the original murderer role is the last relevant action of the murderer, but that this action only becomes such a context when the victim dies. Thus at the time that the original murderer role is played it may not yet be determined that it is in fact a murderer role (though of course in cases when the victim dies straight away it is). In that case we could say that that action is potentially the context for a murderer role, so that at the time of the action the murderer is a potential holder of the original role, and during the time leading up to the victim's death, he is a potential holder of the retrospective murderer role; once the victim dies, these potentialities become actual.

\subsection{Prospective roles}

Retrospective roles naturally arise in cases where the completion of the event coincides with the time at which the process associated with the event comes to an end. But there are examples of events for which, at least under one natural interpretation, the completion marks the beginning of the associated process. An example is departure, which forms the context for an original departing-passenger role. While we could, to be sure, think of departure as the culmination of a process of preparation for departure (travelling to the station, buying a ticket, getting on the train, and so on), what makes it a departure is what comes next, namely the motion of the train out of the station. The interesting thing is that we often use the phrase 'departing passenger' to refer to people undergoing the processes preparatory to the actual departure. This is a derived role, which is played before the original role from which it is derived; it is a prospective role, in contrast to the retrospective roles discussed in the preceding section.

There is an important lack of symmetry between prospective and retrospective derived roles. To be a murderer, it is necessary that one has actually murdered someone, and in general, in order to play a retrospective derived role it is necessary to have played, at some point in the past, the original role from which it is derived. For someone to be a departing passenger, on the other hand, it is not necessary that they will eventually depart; rather, they must be in a situation characterised by an inherent forward-looking reference to an expected future departure. This forward reference can be established by, for example, the fact of having bought a ticket for the departure in question, or having registered the intention to participate in the departure in some other way (for example by waiting at the place of departure or joining the right queue). Normally anyone in such a situation will indeed depart, thereby also playing the original role from which the prospective role is derived, but it is perfectly possible that at the last minute something may prevent the passenger from departing.

This lack of symmetry arises from the inherent asymmetry of time itself, or at least of our experiential and cognitive relation to it. This asymmetry does not mean that at the time a prospective derived role is being played, it can only be ascribed to the player provisionally. Someone described as a departing passenger may in the end fail to depart, perhaps because they change their mind or because the train is cancelled. This would not mean that they had not been a departing passenger after all. Similarly, the original role of candidate, whether for an examination or an election, which is played while the examination or election is actually taking place, gives rise to a prospective derived role which is played during the time from when the role-holder's candidacy is first declared (by whatever means) until the time of the examination or election itself - or, exceptionally, until the candidate withdraws their candidacy or the examination or election is cancelled. 
Another distinction that is illustrated by these examples cuts across the prospective/retrospective division. To be a murderer, it is not just necessary, but also sufficient to have murdered someone. This implies that once one has become a murderer, one is always a murderer - one cannot stop being a murderer in this derived sense. In this sense, the period of validity of the murderer role is unlimited. ${ }^{5}$ But the period of validity of the prospective departing-passenger role is limited, beginning, perhaps, when one first books a ticket, or when one arrives at the station. Thus for someone to count as a departing passenger, it is not sufficient that at some time in the future they will depart, and this prevents this role from having unlimited validity into the past.

There are retrospective roles with limited validity too. An example is applicant (for a job). To play this role it is necessary to have applied for a job, but in addition, one's application must still be "live", that is, the applicant is being considered for short-listing, or has been shortlisted and is awaiting interview, or has been interviewed and is awaiting a decision. Once the appointment has been made, all the applicants to the job cease being applicants, and one of them assumes a new role, that of appointee. This example is discussed further in section 4.2.

The case of candidate differs importantly from departing-passenger in that while both are examples of prospective derived roles, the original departing-passenger role is dependent on an instantaneous event — marking the moment of departure when the train/boat/plane starts moving — whereas the original candidate role is dependent on a process. In the case of a candidate for an examination, this process typically consists of the candidate writing answers or performing pieces (in a music exam), but for a candidate in an election the process need not involve active participation of the candidate at all, being rather marked by the polling stations being open and people coming in to vote. This shows that while prospective derived roles typically come from event-dependent original roles, it is also possible for them to come from process-dependent ones.

In general, however, processes do not give rise to prospective derived roles. Consider, for example, the original process-dependent roles walker and singer, understood simply as someone who is walking or singing. The corresponding prospective derived roles would be played by someone solely by virtue of the fact that they will be walking or singing in the future. Such roles are essentially contentless since there are not, in general, any activities that characterise someone who is going to be walking or singing, and therefore we do not find a need to refer to a person in this position by a name that could designate a role: it suffices to say that someone will be a singer, a simple future-tense reference with no implications for the present. An exception might be if one were to ask 'Who are the singers in next week's concert?', where it might be argued that being signed up to sing in the concert, with the various responsibilities and preparatory activities associated with that, do amount to a substantial role, which may be characterised as the prospective role derived from the original role that is played during the concert itself. But this original role is more than just the plain singer role considered earlier, since it includes also the role of scheduled-performer, which as it were throws its shadow back into the past to give rise to a prospective derived role. This role is not unlike candidate in this respect. ${ }^{6}$

Another interesting feature of the derived candidate role is that it exists in two forms, one prospective and the other retrospective. Up to now we have only considered the prospective form, but it should be noted that one still counts as a candidate after the exam has taken place or the voting has closed, up until the time at which the results of the exam are released or the winner of the election is announced. This retrospective derived role is related to, but clearly different from its prospective counterpart, as can be seen by considering the different activities associated with the two positions - before, studying hard for the exam; after, waiting for the results. Another difference is that whereas the activities associated with the prospective candidacy are in preparation for the process associated with the original role, the activities associated with the retrospective candidacy relate back to the completion of that process (since the result of the examination is derived from the completed exam paper rather than the process of producing it;

\footnotetext{
${ }^{5}$ Other retrospective roles with unlimited periods of validity include author (of a particular book), painter (of a particular painting), and composer (of a particular piece of music). These roles are related to, but distinct from, roles with the same names referring to people who write, paint, or compose, without reference to a specific output.

${ }^{6} \mathrm{But}$ see also the discussion of invited-speaker and related roles in $\$ 5.3$.
} 
the result of the election depends on the total votes cast at the end of the day rather than the process by which votes accumulate while the ballot is open). Hence we suggest that the prospective role is processdependent, whereas the retrospective role is event-dependent; and this is a common pattern which we will find repeated in other examples.

\subsection{Families of Roles}

Pulling together the above observations, we can distinguish a family of four different kinds of occurrentdependent roles (and corresponding role-holders), as follows:

1. Original process-dependent roles such as walker and singer. These roles are played by people who are actually in the process of walking or singing. Notation: $O R_{p r}$.

2. Original event-dependent roles such as murderer and departing passenger, which are dependent on instantaneous events marking the culmination of some process. This kind of role is played only at the moment of culmination (the completion of the act of murder itself, the moment of departure). Notation: $O R_{e v}$.

3. Prospective derived roles which are related to expected future playings of original process- or eventdependent roles, e.g., departing passenger or candidate. Notations: $D R_{p r}^{+}, D R_{e v}^{+}$.

4. Retrospective derived roles which are related to actual past playings of original process- or eventdependent roles, e.g., murderer, witness. Notation: $D R_{e v}^{-}$.

For clarity we shall sometimes use similar annotations in conjunction with particular role-names, thereby distinguishing, for example, murderer $_{e v}$ (the original murderer role) from murderer $_{e v}^{-}$(the retrospective derived murderer role). The two forms of derived candidate role discussed at the end of $\$ 3.3$ can be distinguished as candidate $_{p r}^{+}$and candidate $_{e v}^{-}$, depending on the original roles candidate $_{p r}$ and candidate $_{e v}$ respectively. These four roles together constitute the candidate family; the murderer family contains only two roles since there is no prospective derived role in this case - a person preparing for a murder is not yet a murderer.

Although our main concern in this paper is with occurrent-dependent roles, we will also have occasion to mention object-dependent roles, which we will notate, in the same spirit, using the suffix ' $a b$ ', as, for example, teacher $_{o b}$ or president $_{o b}$.

\subsection{Illustrative case study}

The ideas introduced above may be usefully illustrated by applying them to a scenario comprising a series of stages between someone's initially applying for a job and their subsequently starting work. This is illustrated in Figure 2.

In this diagram we can see:

1. The distinction between object-dependent and occurrent-dependent roles. All the roles here are occurrent-dependent except employee $e_{o b}$. To be an employee is to be part of some organisation and as such the role is dependent on the organisation, which is an object. Each of the other roles in the diagram is dependent on some process or event, and these processes and events are shown on the top line of the diagram. The employee ${ }_{o b}$ role should not be confused with the occurrent-dependent derived role job-starter $e_{e v}^{-}$which is played by the employee for a certain — perhaps rather indefinite — period after starting the job.

2. The distinction between event-dependent and process-dependent roles. Although applying for a job does involve various processes (filling out forms, writing a letter of application, and so on), what matters is the completion of these processes - someone who fills in the forms but neglects to send them off cannot be described as an applicant. Hence the original applicant role is only played by someone at the time the application is submitted and should be denoted applicant eve $_{\text {. One is an }}$ interviewee, however, throughout the process of being interviewed, and it is that process, rather than its completion, that an interviewee prepares for before the event; for this reason the prospective 
role is considered to be derived from interviewee $p$. After the event, on the other hand, when the applicant is awaiting the outcome of the interview, the fact that the interview has been completed is the important thing, so we also include the role interviewee $_{e v}$ which is played at the moment of completion of the interview and gives rise to the derived interviewee $e_{e v}^{-}$.

3. The distinction between prospective and retrospective derived roles. This shows up clearly in the case of applicant ${ }_{e v}^{-}$and interviewee $e_{p r}^{+}$. A person playing these roles has applied for the job, and will be interviewed.

4. Derived roles can be time-limited. Whereas a typical retrospective role, such as murderer $r_{e v}^{-}$and Everest-climber ${ }_{e v}^{-}$, stays with one for life, and even beyond, remaining in force indefinitely far into the future, prospective roles do not hold indefinitely into the past. Thus a person does not play the prospective role interviewe $_{p r}^{+}$until they have been short-listed and invited for interview. But our case study also shows that there are time-limited retrospective roles as well, such as applicant $t_{e v}^{-}$. In contrast with murderer and Everest-climber, this role can become superseded by a later event: once a person has been appointed, their application is no longer "live", so it is no longer appropriate to refer to them as an applicant. ${ }^{7}$

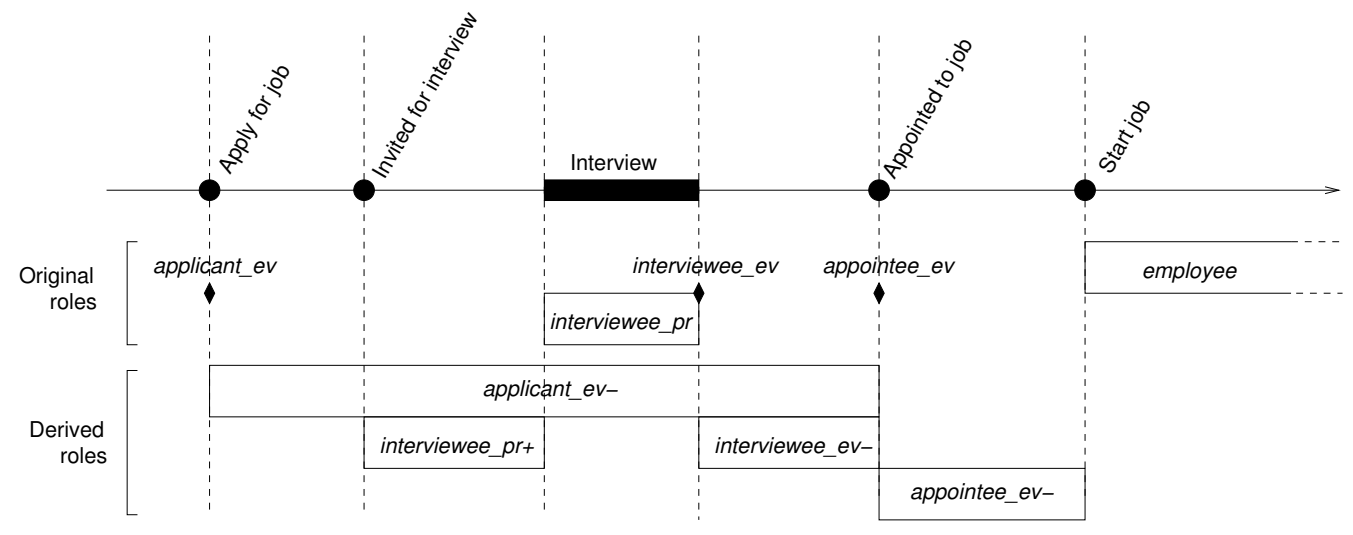

Fig. 2. Roles played by someone applying for a job (for explanation, see §3.5).

\section{The content of a role}

How may a role be characterised? On the one hand we may seek a definition of the role, which in a rigorous formulation may take the form of necessary and sufficient conditions for someone to play the role; on the other hand we may seek a description of the role in terms of typical activities or processes that a holder of the role may be expected to participate in. Both kinds of characterisation contribute to what we call the content of a role, and as we shall see, the relationship between these two kinds of content may differ from one kind of role to another.

More formally, then, we define: ${ }^{8}$

- The definitional content of a role consists of a set of conditions that are jointly necessary and sufficient for a potential player to hold the role.

\footnotetext{
${ }^{7}$ At the risk of labouring the obvious, it should be pointed out that of course one can, after the appointment has been made, refer back to an earlier time and speak of the people who were then applicants; but this concerns the holding of the role applicant ${ }_{\text {ev }}^{-}$ in the past, not the present.

${ }^{8}$ Although we do not discuss such roles in this paper, it should be noted that the distinction between definitional and performable content also applies to 'relational roles' such as owner and neighbour.
} 
- The performable content of a role comprises anything a role-holder does or may do in their capacity as a holder of that role. Note that this can be an open-ended collection of properties not all of which are expected to be performed by every holder of the role.

The simplest cases are original process-dependent roles such as walker $_{p r}$ and singer $_{p r}$ : the content of these roles consists of nothing more than the activities of walking and singing respectively, which provide both the definitional and performable content of these roles.

Object-dependent roles such as schoolteacher ${ }_{o b}$ are more complex. The necessary and sufficient condition for someone to be a schoolteacher is that they are employed in a teaching capacity by a school. But what a schoolteacher actually does qua schoolteacher is a complex collection of activities including not just teaching but also setting and marking homework, making lesson plans, managing a class, being on lunch duty, organising societies, and so on. Thus in this case the performable content goes well beyond what is explicitly stated in the definitional content.

It is worth noting that some of the performable content of a role might consist of the roleholder's taking on additional roles. In the case of schoolteacher ${ }_{o b}$ these roles might be such things as Head-of-Mathematics ${ }_{o b}$ or sports-coordinator ${ }_{o b}$. We shall say that such roles are subordinate to the main role to whose performable content they contribute. In Figure 2, we can see that the roles of the interviewee family are subordinate to the role applicant $t_{e v}^{-}$: being interviewed is one of the activities characteristically associated with being a job applicant. It is no argument against this that not all applicants are interviewed, since the performable content of a role is an aggregation of all the subordinate roles and activities that a player of the role might play or participate in in their capacity as role-holder.

A similar divergence typically occurs in the case of derived occurrent-dependent roles. A good example is murderer $e_{e v}^{-}$. Many different things might happen to someone as a result of their committing a murder: they might go on the run, becoming fugitives from justice (subordinate role: wanted person), be arrested, charged, tried (subordinate role: defendant), convicted (subordinate role: convict), and imprisoned (subordinate role: prisoner). It is important to note that insofar as a murderer participates in any of these processes, he does so specifically as a player of that role, as a murderer, in contrast to other processes such as eating and sleeping, which he participates in merely as a person, not as a murderer. As such, the former processes form part of the performable content of murderer $_{e v}^{-}$, the definitional content in this case consisting only of the fact of having played the original murderer $_{e v}$ role. ${ }^{9}$

Similar processes also form part of the performable content of the derived role criminal $_{\text {ev }}^{-}$, which is played by anyone who has committed a crime; murderer $e_{e v}^{-}$may be regarded as a specialisation of criminal $_{e v}^{-}$and as such inherits its content. But we can refine our description of the processes forming the performable content of murderer so that they specifically relate to murderers rather than other kinds of criminal. The subordinate roles are now wanted murderer, murder defendant, convicted murderer, and imprisoned murderer, and properly speaking it is these refined versions which constitute the performable content of the derived role murderer $e_{e v}^{-}$. This suggests that the elements of the content of a derived role can in every case be specified with reference to the content of the original role from which it is derived: in this case, the original murder role, whose content is just the act of committing a murder.

The content of prospective derived roles can be characterised in similar ways. The original exam-candidate $_{p r}$ role is played by someone while they are actually sitting an exam, an activity which comprises various subordinate activities such as thinking about the questions and writing down answers. The definitional content of the corresponding prospective derived role exam-candidate ${ }_{p r}^{+}$is the mere fact that the person playing the role is due to sit an exam in the future. The performable content comprises any activities or subordinate roles that someone might undertake specifically in consequence of this: such activities as revising lecture notes, doing practice questions, ensuring they are correctly registered for the exam, and making a note of the time and place at which it will be held - all of which, again, are specified with respect to the content of the original role, the sitting of the exam itself. Other activities such as eating and sleeping that are performed by the candidate merely as a person, without reference to the up-coming

\footnotetext{
${ }^{9}$ It is worth pointing out that these subordinate roles can also be played by someone who is not a murderer; it is, after all, not unknown for someone to be wrongly arrested, charged, tried, convicted and even, alas, imprisoned for murder.
} 
exam, do not form part of the content of the derived role - although if a candidate embarks on a special diet in the belief that it will enhance their exam performance then perhaps this too could be included in the performable content of exam-candidate ${ }_{p r}^{+}$.

The picture we have, then, is of a derived role having a simple definitional content, typically described in terms of the role-holder having played (or being about to play) the original role from which it is derived, and a much richer performable content, comprising a range of different processes or activities, which the role-holder may be expected to participate in, forming as it were a visible penumbra around an essentially unobservable central core. Thus we can observe someone waiting on the platform or sitting expectantly in the stationary train, and thereby characterise them as a departing passenger, but we cannot otherwise observe the fact of their being about to depart, although it is this latter fact that provides the defining criterion for the role; similarly, we might observe the murderer being apprehended by the police, tried, and imprisoned, but we cannot usually observe the fact of their having murdered (though if the evidence presented in court is sufficiently vivid and direct we might come close to doing so). Table 1 illustrates these two kinds of content for a number of role-types that we discuss in this paper; the content elements are expressed as predicates (with free-variable $x$ ) which (may) apply to the role-holder. These can be understood as picking out occurrent types; the idea is that a role-holder performs the role by participating in instances of one or more of the occurrent-types in its performable content.

Table 1

Definitional and Performable Content for a selection of role types.

\begin{tabular}{|c|c|c|}
\hline Role & Definitional Content & Performable Content \\
\hline murderer $_{e v}$ & $x$ murders someone & $x$ murders someone \\
\hline murderer $e_{e v}^{-}$ & $x$ has murdered someone & $\begin{array}{l}x \text { is wanted, arrested, tried, convicted, } \\
\text { imprisoned. ... }\end{array}$ \\
\hline exam-candidate $_{p r}$ & $x$ is sitting an exam & $\begin{array}{l}x \text { is sitting an exam (including: writing } \\
\text { answers, thinking about the questions) }\end{array}$ \\
\hline exam-candidate ${ }_{p r}^{+}$ & $x$ is scheduled to sit an exam & $\begin{array}{l}x \text { is revising, arranging transport to the } \\
\text { venue, ... }\end{array}$ \\
\hline exam-candidate $\overline{e v}$ & $\begin{array}{l}x \text { has sat an exam but the re- } \\
\text { sults have not yet been an- } \\
\text { nounced }\end{array}$ & $\begin{array}{l}x \text { is waiting eagerly/nervously/... for } \\
\text { the results }\end{array}$ \\
\hline schoolteacher ${ }_{o b}$ & $\begin{array}{l}x \text { is contracted to work for a } \\
\text { school as a teacher }\end{array}$ & $\begin{array}{l}x \text { teaches classes, sets and marks home- } \\
\text { work, manages a class, organises school } \\
\text { societies, takes playground duty, makes } \\
\text { lesson plans, ... }\end{array}$ \\
\hline singer $_{p r}$ & $x$ is singing & $x$ is singing \\
\hline choirmember ${ }_{o b}$ & $\begin{array}{l}x \text { is a registered member of a } \\
\text { choir }\end{array}$ & $\begin{array}{l}x \text { goes to rehearsals, sings in concerts, } \\
\text { practises at home, participates in and } \\
\text { helps organise choir social events, acts } \\
\text { as a committee member,... }\end{array}$ \\
\hline applicant $_{\text {ev }}$ & $x$ submits a job application & $x$ submits a job application \\
\hline $\operatorname{applicant}_{e v}^{-}$ & $\begin{array}{l}x \text { has applied for a job and the } \\
\text { application is still "live" (i.e., } \\
\text { not rejected) }\end{array}$ & $\begin{array}{l}x \text { is rejected or shortlisted, invited for } \\
\text { interview, preparing for interview, inter- } \\
\text { viewed,... }\end{array}$ \\
\hline
\end{tabular}

In the light of this distinction between two kinds of content, we can now be more precise about exactly what is meant by 'playing' a role. Specifically, we can distinguish holding a role from performing it; we regard these as the two components of playing a role:

- To hold a role $R$ is to satisfy the definitional content of $R$.

- To perform a role $R$ is to participate in some part of the performable content of $R$ while holding $R$. 
It is easy to think of cases where a person can hold a role while not performing it: for example, a teacher is still a teacher when asleep, and in our terminology this state of affairs is exactly characterised by noting that a sleeping person can hold a teacher role but cannot perform it. ${ }^{10}$

Even more: it is possible to hold a role without ever playing it. Think of someone who is appointed as a teacher but before they can start work they fall seriously ill and have to take extended sick leave; eventually they resign from the post, while still on leave. This could happen also in the case of derived roles: for example, if a murderer, after murdering, just gets on with his life as if nothing had happened, and nobody ever suspects him so he is never the target of a police investigation and never brought to justice, then arguably he holds the role murderer $r_{e v}^{-}$but never performs it. Of course, it could be said that even in this case the murderer knows he has murdered, and having this knowledge is something in which he participates as murderer and therefore it forms part of the performable content of the role; so to make the example even more fanciful we could suppose that the murderer develops amnesia immediately after the murder and is unaware that he has murdered.

In contrast to these cases, there are other roles which it is not possible to hold without performing them; these are the original occurrent-dependent roles. In fact, one only comes to hold such roles by performing them. It may be tempting to argue, however, that having started performing the role, one might then be said to continue to hold it even through interruptions in the performance, so that, for example, a singer is still performing as a singer during a five bars' rest in the middle of a song. Here we must refer back to our remarks in $\$ 3.1$ concerning whether processes can admit "gaps". There we concluded that the appearance of gappy processes was an illusion arising from variant interpretations of the verb designating the process: in this case, exactly how broadly or narrowly we should understand 'singing'. At the most basic level, to sing is to produce musical sounds with the voice, and to be a singer $_{p r}$ in this sense one must be singing in this sense; but singing a song, for example, is understood to include any rests during the song when no vocal sounds are produced. If that is what one means by singing, then during the rests one is indeed a singer $_{p r}$. Thus in either case the definitional and performable contents coincide.

In general, the question of just how broadly or narrowly a process-verb is to be understood - and the implications this has for the content of a process-dependent role - is a delicate one. Consider the case of the driver of a car who stops at a service station for a comfort break; if during that time a policeman asks 'Who is the driver of this car?' it may in one sense still be true during the break that the person who was driving it before is the driver. As with singing, we may distinguish between driving narrowly conceived as the activity of actually sitting in the driver's seat and controlling the car, and a somewhat broader view of driving as being the driver of the car for a particular journey. On both views, driver is an original process-dependent role: the difference lies in what the process in question is taken to be. An interesting case is where a couple share the driving, with the husband taking over the driving from his wife after the service-station break. In this case there is no straightforward answer to the policeman's question. But on either view of driving, one only holds the role rriver $_{p r}$ by actually performing it.

A final note in this section: Although 'perform' connotes something active, some roles are essentially passive and as such are 'performed' as it were by proxy, through the active performance of some element other than the role-holder. We have already seen this in the case of an election candidate: the active part of being a candidate is campaigning, and that happens exclusively before the election, forming part of the performable content of candidate $_{p r}^{+}$; during the election itself, when the role candidate $_{p r}$ is held, all the 'performing' is done by the voters and those manning the polling stations; and similarly the performable content of candidate $_{e v}^{-}$is in the hands of those counting the votes. As one might expect, this kind of "passive performance" is particularly to be expected in the case of inanimate role-holders such as destination and obstacle. We would argue that destination is the prospective derived role corresponding to the original passive role be-arrived-at-by. Thus, for example, Mary's destination is a place which Mary is expected to arrive at. This role is held by a place so long as Mary is intent on reaching it; it is performed by

\footnotetext{
${ }^{10}$ The distinction between holding a role and performing it is closely related to that between two senses of play introduced in (Mizoguchi et al.,2012a), which capture the distinction between being having been assigned a role (play_1) and actually realising it (play_2). In essence this is the same distinction, so long as one understands 'assign' sufficiently broadly to mean that to be assigned a role is just to satisfy the necessary and sufficient conditions for holding it.
} 
the place so long as Mary is actually travelling towards it with that intention. A comparable analysis for obstacle should be possible, but requires care.

\section{Some problematic cases}

In this section we consider a number of problematic cases to illustrate some further subtleties of our theory.

\section{1. 'Choice'}

When someone chooses between a number of alternatives, the alternative chosen is called their choice. Here choice is an original role played by the alternative at the moment of its being chosen: in our notation it is choice $_{e v}$. But we still talk about choices before the moment of choosing: 'There are three choices of flavour available'. In this case we are dealing with a prospective derived role choice $e_{e v}^{+}$. As always with prospective roles, it is possible for something to play it without eventually playing the original role from which it is derived; in the case of choice $e_{e v}^{+}$we know, by the nature of things, that in any given choice situation all but one of the players of this will end up not playing the role choice $_{e v}$. After the choice has been made, we still refer to the chosen alternative as a choice; in this case it is choice $_{e v}^{-}$.

To summarise, choice $e_{e v}^{+}$refers to any of a set of alternatives available to be chosen, choice $_{e v}$ refers to that alternative which actually is chosen, at the time of choosing, and choice $e_{e v}^{-}$refers to the chosen alternative after it has been chosen (for as long as the fact of its having been chosen is meaningful). This family of roles aligns neatly with the three components of a nucleus in Moens and Steedman's theory (1988): preparatory process, culmination, and consequent state. In this case the preparatory process is purely passive, any activity involved being on the part of the person doing the choosing rather than of the things available to be chosen.

The choice roles are closely related to the election-candidate role, since electing a candidate is indeed making a choice - although this case is more complicated since the choice is made collectively, being derived by a kind of aggregation from the choices of the individual electors. But again, one is no longer a candidate after one has been elected (or failed to be elected), so there is no corresponding retrospective role. In the case of the other use of 'candidate', as an exam candidate, it is possible that all the candidates are successful. We might think of this as being 'chosen' by the examiners, but the nature of the situation is very different, making it less natural to describe it in this way.

\section{2. 'Witness'}

Here we consider further the case of witness which was mentioned briefly in $\S 3.2$, although glossing over the niceties. In fact the exact nature of witnessing depends on the nature of what is witnessed. To witness an event is an event, but to witness a process could be either an event or a process: you can merely catch sight of someone in the act of walking, say, or you can follow the process attentively. For a durative event, the unfolding of which involves a process, witnessing the event is an event, the unfolding of which involves witnessing the process: in such a case one is witness $s_{p r}$ while one is actually watching the event in progress, and is then fleetingly witness $s_{e v}$ at its completion. Thus witnessing can be either processdependent or event-dependent. However, what one might subsequently testify to is always a witnessing event: in the case of witnessing a pure process, it is enough to catch sight of the process, and this is an event, regardless of whether or not one continues watching; and for witnessing an event, it is necessary to witness its completion, which is again an event. Compare: 'Did you see the defendent beating his wife?' (to truthfully answer 'yes' it is enough to have caught sight of the beating) and 'Did you see the defendent beat his wife for five minutes?' (for this one must have completed five minutes' worth of watching the beating). Thus the retrospective role is always witness $e_{e v}^{-}$.

To add to the complications, in English the word 'witness' has three distinct but related meanings: a witness to an event, a witness testifying in court, and a person witnessing a signature to validate a 
contracting process. Let us designate these three roles witness1, witness2, and witness3. Up to now we have only discussed witness1. It is noteworthy that in Japanese there are three different words for these roles, ${ }^{11}$ which perhaps supports the idea that what we are doing in this paper is ontological, not linguistic, analysis.

The three kinds of witness differ in some significant respects. For example, the original witness2 role is process-dependent (witness $2_{p r}$ ), since what is important is the process of giving testimony, which is not something that by nature moves towards a well-defined completion. By contrast, witness3 is eventdependent, since what matters is the completion of the process by the witness appending their signature to the document. The three witness roles also differ in the kinds of derived roles they admit. Since a witness2 and, in most cases, a witness 3 is formally designated as such before the actual witnessing is performed, there is a clear use for witness $2_{p r}^{+}$and witness $3_{p r}^{+}$. But this never happens with witness1: a player of this role can only be described as a witness during or after the event that they witness. The retrospective role witness $1_{\text {ev }}^{-}$, on the other hand, is important and is frequently encountered: it designates someone as having witnessed an event. Such a person might, if the event is of a serious nature, be called upon to give testimony in court; we can say, therefore, that the role witness2 $2_{p r}$ forms part of the performable content of witness $1_{e v}^{-}$. This does not work the other way round, though, since not all people witnessing in court are there because they have witnessed an event - an expert witness may be called to give testimony based on their specialist knowledge of some relevant science, for example.

\section{3. 'Invited speaker', 'conference chair', etc}

At first glance, invited-speaker appears to be an occurrent-dependent role referring to someone who is giving an invited talk at a conference. But of course we do not only call someone an invited speaker while the talk is in progress: in fact invited speakers are usually fixed a considerable time before the conference, and during that time they will be engaged in activities such as writing a paper, preparing slides, and making travel arrangements, which are directly related to their role as invited speaker. On the view that the original role here is that of actually presenting the talk, these preparatory activities must be regarded as belonging to a derived role, invited-speaker ${ }_{p r}^{+}$, of which they form the performable content.

Plausible though this may seem, it is somewhat problematic. Indeed, invited-speaker is just one role amongst several that are associated with a conference; other examples include conference-chair, programme-committee-member, reviewer, and presenter. Like invited-speaker, these roles are assigned well before the start of the conference itself, and in most such cases the greater part of the work done in these capacities actually happens before the conference. If we take the prima facie view of these roles as occurrent-dependent roles whose context is the conference or some part of it, considered as an occurrent, then as suggested in the case of invited-speaker, all this work prior to the conference would have to be regarded as performable content relating to prospective derived roles such as conference-chair $r_{p r}^{+}$ and programme-committee-member ${ }_{p r}^{+}$. But that could only be the case if the work done before the conference could be viewed as a preparation for their participation in the conference; for a programme committee member, at least, this is emphatically not the case since it is quite usual for programme committee members not to attend the conference at all, without this being considered to diminish their performance of the role. Even in the case of invited speakers, where attendance at the conference is a required part of the role, it is worth pointing out that the role includes not just preparing and giving their talks, but also, for example, raising the profile of the conference by having their names listed on the website, which again cannot be seen as preparation for what they do during the conference itself.

These conference-dependent roles are in some ways analogous to school-dependent roles like teacher which we considered earlier. The teacher role is assigned to someone when they are appointed as a teacher, and they explicitly play that role by participating in a variety of activities which take place during the time that they hold the role: these activities form the performable content of the role. Even when not participating in such activities, for example when asleep or at home watching television, they can still be

\footnotetext{
${ }^{11}$ mokugekisha (目撃者), shounin (証人), and tachiainin (立会人) respectively.
} 
said to be a teacher. Similarly, during the time that one is designated as a conference chair, programme committee member, or indeed invited speaker, there are various activities one participates in precisely in those capacities, but for a good deal of the time over which one holds these roles one is not actively performing them.

In the light of this, a plausible solution to the problem of conference-related roles is that they are dependent not on the conference as an event but on the conference organisation as an object. Just as a school comprises various different roles such as head ${ }_{o b}$, secretary $y_{o b}$, teacher $_{o b}$, so a conference organisation comprises the roles under discussion here such as chair $r_{o b}$, programme-committee-member ${ }_{o b}$,

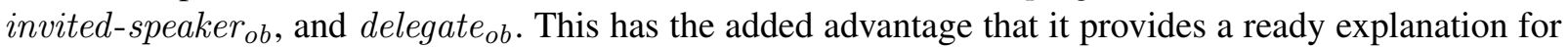
cases where these roles are unfilled. Once the conference organisation is set up, various positions on the organising committee may be defined before anyone is appointed to them: the roles are created before the corresponding role-holders. This cannot easily happen with occurrent-dependent roles.

It remains true that the conference itself is an event, and indeed there are event-dependent roles that are played during it, for example a person who asks a question after a talk. Some roles may have closely related object-dependent and event-dependent forms: presenter, considered as someone who has submitted a paper which has been accepted for presentation at the conference, should be regarded as dependent on the conference-organisation object, and therefore as presenter $_{o b}$; they hold the role from the moment their paper has been accepted, and they play it not only when presenting the paper at the conference itself but also when preparing camera-ready copy for the proceedings and slides to show during the presentation; during the presentation itself they are also playing the occurrent-dependent role presenter $_{p r}$, that is, someone who is actually presenting a paper. This role also forms part of the performable content of the invited-speaker ${ }_{o b}$ role.

\subsection{Habitual roles: cyclist, singer, etc.}

If we say that a cyclist passed us on the road, then we are using the term 'cyclist' to mean someone who is currently cycling, that is, performing the original process-dependent role cyclist $_{p r}$. But if we say that several of our colleagues are cyclists, we do not mean that they are actually cycling at that time, but rather that they habitually cycle. This sense of 'cyclist' therefore refers to a different role, which we might call a habitual role; let us denote this cyclist $_{h a b}$. Many other nouns formed from verbs in this way, such as singer, smoker, and reader, can similarly be used to denote either original process-dependent roles $\left(\mathrm{X}_{p r}\right)$ or habitual roles $\left(\mathrm{X}_{h a b}\right)$. How should such roles be analysed?

One possibility would be to regard habitual roles as an addition to the family of occurrent-dependent roles. Just as the original roles are related to the present progressive form of the verb ('is singing', 'is murdering'), retrospective roles are related to the perfect tense ('has murdered'), and prospective roles to the future tense ('will depart'), so it seems that habitual roles could be related to the habitual use of the simple present ('sings', 'cycles'). On the basis of this observation we might then characterise the habitual roles as habitual derived occurrent-dependent roles.

In that case, the role cyclist $_{h a b}$ would be dependent on an occurrent. But precisely what occurrent? One becomes a habitual cyclist by cycling with sufficient frequency and/or regularity; how many individual cyclings does it take? It is impossible to define this precisely; it might vary from case to case. In fact we are asking how many times someone must cycle (sing, smoke, read, ...) for them to have the habit of cycling (etc.). Whatever answer we give in a particular case, if someone can be correctly said to hold the role cyclist $_{\text {hab }}$, this must be because they have acquired the habit of cycling. What this suggests is that a role such as cyclist $_{h a b}$ should be dependent, not on any particular set of occurrences of cycling, but on the habit of which those occurrences are manifestations. A habitual role, in other words, might be a habit-dependent role.

Ontologically, what is a habit? A habit is not an occurrent: one has a habit, one does not do it. If it is not an occurrent, then it must be a continuant of some kind. While habits bear some similarity to dispositions, which are generally regarded as dependent continuants, there are clear differences between the two categories. One can have a disposition to $\mathrm{X}$ without ever actually Xing, but to have the habit of 
Xing one must actually X, and moreover must do so "sufficiently" often. Habits resemble dispositions in being dependent on their bearers, but unlike dispositions they are also dependent on the actual occurrents through which they are manifested. Habit-dependent roles are therefore dependent on continuants which are themselves dependent: a habitual role is dependent on a habit which is in turn dependent on both the player of the role and the occurrents through which it is manifested.

If we accept this account (and here we merely propose it as a possibility), then our taxonomy of roles would be as follows:

1. Continuant-dependent

1.1. Object-dependent $\left(X_{o b}\right)$

1.2. Habit-dependent $\left(X_{h a b}\right)$

2. Occurrent-dependent

2.1. Original $\left(X_{p r}, X_{e v}\right)$

2.2. Derived

2.2.1. Retrospective $\left(X_{e v}^{-}\right)$

2.2.2. Prospective $\left(X_{p r}^{+}, X_{e v}^{+}\right)$

Within this taxonomy we can make useful distinctions between different roles with the same name. In the case of writer, for example, we have:

- writer $_{p r}$, someone who is actually writing

- writer $_{e v}^{-}$, someone who has written something (e.g., the writer of a letter one has received, or a book that has been published)

- writer $_{h a b}$, someone who is in the habit of writing

- writer $_{o b}$, someone who is employed as a writer as part of an organisation (e.g., a newspaper)

Similar analyses could be given in many other cases.

Habitual roles are closely related to the original occurrent-dependent roles with the same name, because the latter form part of the performable content of the former. One holds the role cyclist $_{h a b}$ by possessing the cycling habit; one can perform it by performing the role cyclist $_{p r}$. The performable content of cyclist $_{\text {hab }}$ could also include other activities such as cycle maintenance, joining a cycling club, searching the web for information on the latest makes of bicycle, and so on; but unlike the regular performance of cyclist $_{p r}$ none of these is an obligatory component of the role.

\subsection{When do derived roles make sense?}

Although it is possible in theory to form prospective and retrospective derived roles from any original occurrent-dependent role, how much these derived roles really make sense depends on the original process or action which constitutes the context for the original role. For a simple process-dependent role such as walker $_{p r}$, we do not normally find a need to invoke either of the derived roles. A person playing the walker $_{p r}^{+}$role would be someone who is going to walk; as already noted, this is usually signalled simply by the use of the future tense and we do not use the term 'walker' for this. Similarly, instead of calling someone a walker ev , with reference to a past completion of an episode of walking, we would simply say that they have walked.

There are, however, contexts in which it could be argued that 'walker' takes on a more structured meaning. Imagine a case where a youth group has organised a day of activities, where individuals can sign up for walking, climbing, or swimming. At the start of the day, before any of the activities have begun, the organiser instructs the walkers, the climbers, and the swimmers to report to their respective leaders. Here 'walker' is used to refer, not to people who are walking, but to people who are intending to walk. In this case it might be said that they hold a prospective role walker $_{p r}^{+}$. After the activities have finished, during the evening debriefing, the organiser might call on the walkers to give an account of their day's activities: these people now play the role walker $_{e v}^{-}$. 
Similar remarks might be applied to the case of singer: after a concert someone might stand up and say 'I would like to congratulate all the singers on their performance'. What role is referred to by 'singer' here? Does it mean people who were singers during the concert, or does it mean people who now count as singers by virtue of having sung? The more parsimonious explanation is the former; but if we think of the singing here specifically as participation as a performer in the concert, then it may be appropriate to invoke a retrospective singer $e_{e v}^{-}$role here, which in this case could be regarded as a specialisation of the event-dependent role performer $r_{e v}^{-}$held by someone by virtue of having performed by singing.

Despite these special cases, it remains true that in general process-dependent roles do not give rise to derived roles. A more exact reason for this concerns the nature of the actions or process constituting the occurrent in question. Walking and singing are essentially both processes or activities, and are not in themselves characterised in terms of the achievement of some salient end-result. Yet it is precisely when such an achievement is important that the retrospective derived role makes sense, since it can be used to describe the status of someone who has that achievement to their credit (or shame!). This is why the retrospective roles such as murderer ${ }_{e v}^{-}$and Everest- climber $_{e v}^{-}$make sense. Other examples include prizewinner $_{e v}^{-}$, marathon-runner $e_{e v}^{-}$, divorcee $e_{e v}^{-}$, appointee $e_{e v}^{-}$, choice $_{e v}^{-}$(\$5.1), and witness $_{e v}^{-}$(§5.2). Performing in a concert might similarly be regarded as an achievement, focussing on the successful completion of the performance rather than the process, making it appropriate to use the retrospective derived role performer $r_{e v}^{-}$.

Apart from choice, however, none of the roles just listed admits a prospective derived role; in general prospective roles are less commonly encountered, because they require the original role to be such that someone who is in some way scheduled or expected to perform it thereby acquires a special status that is typically marked by various activities (such as preparation) which can form the performable content of the prospective derived role. This works for roles such as departing-passenger, choice, and candidate, as discussed above, since in these cases, we do find it convenient to refer to someone or something as being currently in a state which is defined by a forward-looking reference to their playing the respective original role (actually departing, being chosen, sitting the exam or being voted for).

To what extent are these matters ontological rather than linguistic? Language can guide ontological investigations, but ontology can help to explain linguistic phenomena too. The reason why we find it natural to use some role terms in a prospective or retrospective derived sense is primarily ontological, concerned with the nature of the roles described by them; for this reason, it is often helpful to turn to language in order to uncover important ontological distinctions. It is not always easy to tell whether differences between languages are superficial or reveal different ontological presuppositions on the part of speakers of the languages. A typical case is where a group of related roles are covered by a single term in one language and distinguished by different terms in another - as in the case of the three Japanese translations of 'witness'. From an ontological point of view we could say that both the distinctness of the roles and their family resemblance are grounded in reality; the two languages thus focus on different aspects of the reality - it would be inappropriate to say that one is "right" and the other "wrong", ontologically speaking.

\section{A step towards formalisation}

\subsection{Primitive predicates}

As a starting point for the formalisation, we treat the following one-place predicates as primitives. In this listing, we also introduce the letters or strings by which we shall standardly designate variables used as arguments for the predicates (though from a logical point of view all variables are interchangeable - these choices are for readability purposes only). All entities are to be understood as particulars, not universals.

- Entity(en): en is an entity

- Object (ob): ob is an object

- Occurrent(oc): oc is an occurrent

- Event $(e v): e v$ is an event 
- Process $(p r): p r$ is a process

- Role $(r): r$ is a role (that is, a particular instance of a role concept)

- Roleholder $(h): h$ is a role-holder

- Time $(t): t$ is a time point

The first set of axioms specifies the subsumption hierarchy for the classes corresponding to these predicates: ${ }^{12}$

Ax1.1 Entity $($ en $) \rightarrow$ Continuant $($ en $) \oplus$ Occurrent $($ en $)$

Ax1.2 Continuant $(c o) \rightarrow$ Object $(c o) \oplus$ DependentContinuant $(c o)$

Ax1.3 DependentContinuant $(d c) \rightarrow$ Role $(d c) \oplus$ Roleholder $(d c) \oplus \cdots$

Ax1.4 Occurrent $(o c) \rightarrow$ Event $(o c) \oplus$ Process $(o c)$

Ax1.3 is left incomplete - the '...' is to be replaced by whatever other dependent continuants, such as functions, dispositions, or habits, one wants to cover. For our present purposes it is unnecessary to specify these. Also note that here we only handle object-roles; to accommodate occurrent-roles, which were mentioned in the introduction but not otherwise discussed in this paper, the formalism would need to be modified slightly.

We next introduce the following primitive relational predicates:

- Context-of $(r, e n)$ : The context of role $r$ is entity en.

- Holds $(e n, r, h, t)$ : Entity en plays role $r$ as role-holder $h$ at time $t$.

- Part-of $\left(e n, e n^{\prime}, t\right)$ : Entity en is part of entity $e n^{\prime}$ at time $t$.

- Participates-in(en,oc,t): Entity en participates in occurrent $o c$ at time $t$

- Present $(e n, t)$ : Entity en is present at time $t$.

The next set of axioms specifies the domain of arguments for each of the primitive relational predicates:

Ax2.1 Context-of $(r$, en $) \rightarrow$ Role $(r) \wedge \operatorname{Entity}($ en $)$

Ax2.2 Holds $(e n, r, h, t) \rightarrow \operatorname{Entity}(e n) \wedge$ Role $(r) \wedge$ Roleholder $(h) \wedge \operatorname{Time}(t)$

Ax2.3 Part-of $\left(e n, e n^{\prime}, t\right) \rightarrow \operatorname{Entity}(e n) \wedge \operatorname{Entity}\left(e n^{\prime}\right) \wedge \operatorname{Time}(t)$

Ax2.4 Present $(e n, t) \rightarrow$ Entity $($ en $) \wedge$ Time $(t)$

Ax2.5 Participates-in $($ en $, o c, t) \rightarrow$ Entity $($ en $) \wedge \operatorname{Occurrent}($ oc $) \wedge \operatorname{Time}(t)$

A number of axioms are needed to establish further connections between the primitive predicates:

Ax3.1 Context-of $(r, e n) \wedge$ Context-of $\left(r, e n^{\prime}\right) \rightarrow e n^{\prime}=e n$

Ax3.2 Context-of $(r, e n) \rightarrow \exists$ t.Present $(e n, t)$

Ax3.3 Roleholder $(h) \leftrightarrow \exists e n, r$, t.Holds $(e n, r, h, t)$

Ax3.4 Holds $(e n, r, h, t) \wedge$ Holds $\left(e n^{\prime}, r^{\prime}, h, t^{\prime}\right) \rightarrow e n=e n^{\prime} \wedge r=r^{\prime}$

Axiom 3.1 asserts that if a role has a context, it is unique. In the light of previous discussion, it might be thought that a role must have a context; however, in the case of prospective derived roles, a potential context may never actually be present, and axiom 3.2 stipulates that a context must be present at some time. For further discussion of this point, see below. Axiom 3.3 ensures that a roleholder is always assocated with a player, a role, and a time, and axiom 3.4 says that the player and the role for a given roleholder are unique. The time need not be unique, however, since a role may be played by the same player over an interval, encompassing many time points, and the same roleholder persists over that interval.

\subsection{Defined predicates}

Additional predicates are defined as follows:

${ }^{12}$ Here we are using $\oplus$ to indicate the exclusive-or operator. 
Df1.1 Held-at $(r, t)=_{\text {def }} \exists e n, h . H o l d s(e n, r, h, t)$

Df1.2 ObjDepRole $(r)=_{\text {def }} \operatorname{Role}(r) \wedge \forall$ ob $($ Context-of $(r, o b) \rightarrow \operatorname{Object}(o b))$

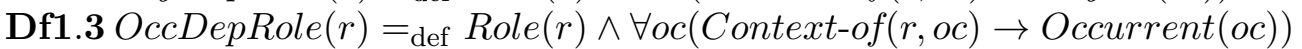

Df1.4 OR $(r)==_{\text {def }}$ OccDepRole $(r) \wedge \forall o c, t($ Context-of $(r, o c) \wedge$ Held-at $(r, t) \rightarrow \operatorname{Present}(o c, t))$

Df1.5 $D R(r)={ }_{\text {def }}$ OccDepRole $(r) \wedge \neg O R(r)$

Df1.6 $D R^{-}(r)=_{\text {def }} D R(r) \wedge \forall$ oc, $t, t^{\prime}\left(\right.$ Context-of $(r, o c) \wedge$ Held-at $(r, t) \wedge \operatorname{Present}\left(\right.$ oc, $\left.\left.t^{\prime}\right) \rightarrow t^{\prime}<t\right)$

Df1.7 $D R^{+}(r)=_{\text {def }} D R(r) \wedge \forall o c, t, t^{\prime}\left(\right.$ Context-of $(r, o c) \wedge$ Held-at $(r, t) \wedge \operatorname{Present}\left(\right.$ oc,$\left.\left.t^{\prime}\right) \rightarrow t<t^{\prime}\right)$

Thus, Held-at $(r, t)$ means that role $r$ is played at time $t$; definitions 1.2 and 1.3 introduce object- and occurrent-dependent roles respectively; definitions 1.4 and 1.5 introduce original and derived occurrentdependent roles; definitions 1.6 and 1.7 distinguish retrospective and prospective derived roles.

\subsection{Theory of occurrent-dependent roles}

From the definitions, it follows trivially as a theorem that any occurrent-dependent role is either an original role or a derived role, but not both:

Th1 OccDepRole $(r) \rightarrow O R(r) \oplus D R(r)$.

It does not, however, follow that every derived role is either prospective or retrospective, since on the basis of the axioms listed so far it ought to be possible to have a derived role which is played both before and after its context is present and hence is neither prospective nor retrospective. In practice, we would always want to split such a mixed derived role into its prospective and retrospective components - compare the discussion of the prospective and retrospective versions of the candidate role at the end of section 3.3. To ensure this we introduce the axiom

$\mathbf{A x 4 . 1} D R(r) \rightarrow D R^{+}(r) \oplus D R^{-}(r)$

which is the first of a series of key axioms featuring the defined predicates. Further axioms of this series follow.

First, the holder of an object-dependent role is part of the context of the role, whereas the holder of an occurrent-dependent role participates in the context of the role:

Ax4.2 ObjDepRole $(r) \wedge \operatorname{Holds}(e n, r, h, t) \wedge$ Context-of $(r, o b) \rightarrow \operatorname{Part-of}(h, o b, t)$ Ax4.3 OccDepRole $(r) \wedge$ Holds $($ en $, r, h, t) \wedge$ Context-of $(r, o c) \wedge \operatorname{Present}\left(\right.$ oc, $\left.t^{\prime}\right) \rightarrow$

Participates-in $\left(h, o c, t^{\prime}\right)$

Note that in Axiom 4.3 it is necessary to specify the time at which the context is present, since this may differ from the time that the role is played. Note also that we use the variable $o b$ in 4.2 to remind the reader that in this case the context is an object (definition 1.2), but oc in 4.3 since there the context is an occurrent (definition 1.3).

The definition of an original role states that its context is present when the role is played. By axiom 4.3, this means that the player of the role participates in the context of the role at that time. This is stated in the following theorem, which can be regarded as a simplified form of axiom 4.3 for original roles, analagous to axiom 4.2 for object-dependent roles:

Th2 OR $(r) \wedge$ Holds $($ en $, r, h, t) \wedge$ Context-of $(r, o c) \rightarrow$ Participates-in $(h, o c, t)$.

In axioms 4.2 and 4.3 the parthood and participation of the player in the context is conditional on the context actually existing, but as we have noted, this need not be the case for prospective derived roles. In fact it is only in that case that we want to allow this context-failure to occur, so to ensure this we introduce a further axiom

Ax4.4 Role $(r) \wedge \neg D R^{+}(r) \rightarrow \exists$ en.Context-of $(r, e n)$

Using this axiom we can refine axiom 4.2 and theorem 2 as follows: 
Th3 ObjDepRole $(r) \wedge$ Holds $(e n, r, h, t) \rightarrow \exists o b(\operatorname{Context-of}(r, o b) \wedge \operatorname{Part-of}(h, o b, t))$

Th4 OR $(r) \wedge$ Holds $($ en $, r, h, t) \rightarrow \exists o c($ Context-of $(r, o c) \wedge$ Participates-in $(h, o c, t))$.

A similar reformulation of axiom 4.3 is possible in the case of retrospective derived roles. This relies on axioms 3.2, 4.3, and 4.4, which together with the relevant definitions result in

Th5 $D R^{-}(r) \wedge \operatorname{Holds}(e n, r, h, t) \rightarrow \exists o c, t^{\prime}\left(\right.$ Context-of $(r, o c) \wedge t^{\prime}<t \wedge$ Participates-in $\left.\left(h, o c, t^{\prime}\right)\right)$.

For prospective derived roles, however, we cannot take advantage of axiom 4.4 to guarantee the actual existence of the context of the role. Here we are dealing with cases like candidate ${ }_{p r}^{+}$and departing-passenger ${ }_{e v}^{+}$discussed previously, where it is always possible for an exam, an election, or a departure to be cancelled without falsifying the status of the would-be participants up to that point as candidates or departing passengers. In this case the holding of the prospective role is conditional, not upon the actual existence of a future context on which it could depend, but on some kind of expectation or foreshadowing of such a context. To handle this within our logical formalisation one possibility is to go beyond the resources provided by first-order logic and make use of some form of modal possibility operator $\diamond$.

Tentatively, we might write

Ax4.5? $D R^{+}(r) \rightarrow \diamond \exists o c$. Context-of $(r, o c)$,

while acknowledging that this does not say much until we have specified the required semantics for $\diamond$; this would require a careful analysis of the kinds of modality involved in the idea that, for example, the passengers expect to depart. Assuming we have this, then the analogue of theorems 3 and 4 for prospective derived roles could be

Th6? DR $R^{+}(r) \wedge$ Holds $(e n, r, h, t) \rightarrow$

$$
\diamond \exists o c, t^{\prime}\left(\text { Context-of }(r, o c) \wedge t<t^{\prime} \wedge \text { Participates-in }\left(h, o c, t^{\prime}\right)\right),
$$

which says that when en plays the role $r$ as $h$, a context for $r$, with $h$ participating in it, may occur in the future. Precisely what this means depends, as indicated above, on the semantics of the modal operator; we leave this unspecified here but signal it as an important issue to be settled before full formalisation is possible.

Setting this issue aside, we now turn to the definition and characterisation of event- and processdependent roles. These broadest categories can be defined straightforwardly as follows:

Df2.1 EvDepRole $(r)=_{\text {def }} \operatorname{Role}(r) \wedge \forall e v($ Context-of $(r, e v) \rightarrow$ Event $(e v))$

Df2.2 ProcDepRole $(r)=_{\text {def }} \operatorname{Role}(r) \wedge \forall p r($ Context-of $(r, p r) \rightarrow \operatorname{Process}(p r))$

The distinction between processes and events can be expressed through the following axioms:

Ax5.1 Event $(e v) \rightarrow \exists t \forall t^{\prime}\left(\right.$ Present $\left.\left.\left(e v, t^{\prime}\right) \leftrightarrow t^{\prime}=t\right)\right)$

$\operatorname{Ax} 5.2 \operatorname{Process}(p r) \rightarrow \exists t \exists t^{\prime} \forall t^{\prime \prime}\left(\operatorname{Presen} t\left(p r, t^{\prime \prime}\right) \leftrightarrow t<t^{\prime \prime}<t^{\prime}\right)$

Note that these axioms presuppose a particular view of events and processes, which may be too restrictive for general use, but provides what we require for the present theory of roles. Thus, axiom 5.1 restricts events to instantaneous events: it says that there is a unique moment of time at which the event is present. This is in keeping with the idea that what is important for event-dependent roles is the completion of an event - so in effect, axiom 5.1 identifies any event with its instantaneous culmination. Similarly, axiom 5.2 stipulates that a process instance is present at each moment within some open convex interval.

The role types $O R_{e v}, O R_{p r}, D R_{e v}^{ \pm}, D R_{p r}^{+}$can all be defined using the following schema: ${ }^{13}$

Df2.3 $\alpha R_{\beta}^{\gamma}(r)=_{\text {def }} \alpha R^{\gamma}(r) \wedge \beta \operatorname{DepRole}(r)$,

where $\alpha \in\{O, D\}, \beta \in\{E v$, Proc $\}$, and $\gamma \in\{\lambda,+,-\}$ (where $\lambda$ is the empty string).

${ }^{13}$ The case $D R_{p r}^{-}$, which appears to be unrealised, should be excluded here. 


\subsection{Content of a role}

Next, we consider the performable content of a role and the distinction between holding a role and performing it. As discussed in section 4, the performable content may be thought of as a collection of occurrent-types. Although up to this point our formalisation has operated entirely at the level of instances, we cannot proceed further without introducing types, specifically occurrent types. In keeping with widespread ontological practice, we are prepared to treat types as first-order objects, representing them by means of terms rather than predicates; this enables us to introduce predicates over types without departing from a first-order formalism.

In order to formalise these ideas, we introduce new predicates as follows:

- OccType (ot): ot is an occurrent type

- Performable (ot, $r)$ : ot is part of the performable content of $r$

- Performs $(h, t)$ : role-holder $h$ performs its role at time $t$

Note that in Performs $(h, t)$ it is not necessary to specify the role using an extra argument $r$ since this is uniquely determined by the roleholder. The required argument-restriction axioms are as follows:

Ax6.1 Performable $($ ot,$r) \rightarrow$ OccType $($ ot $) \wedge$ Role $(r)$

Ax6.2 Performs $(h, t) \rightarrow$ Roleholder $(h) \wedge$ Time $(t)$

The definition of performance of a role can now be given as

$$
\begin{array}{r}
\text { Df3.1 Performs }(h, t)==_{\text {def }} \exists e n \exists r \exists o t \exists o c(\operatorname{Holds}(e n, r, h, t) \wedge \operatorname{Performable}(\text { ot }, r) \wedge \\
\text { Instance-of }(o c, \text { ot }) \wedge \operatorname{Participates-in}(h, o c, t))
\end{array}
$$

In other words, a roleholder performs its role just when, qua holder of that role, it participates in an instance of an occurrent type belonging to the performable content of the role.

\subsection{Properties of role-holders}

It will be noticed that in Axioms 4.2 and 4.3, and theorems derived using them, it is the roleholder, rather than the entity playing the role, that is said to form part of or participate in the context of a role, and it is appropriate here to say a little about how the properties ascribed to a role-holder are related to the properties of the underlying entity. Although we have stated (in §2.2) that a role-holder inherits all the properties of the entity playing the role, in addition to those further properties that the entity can only be said to possess in their capacity as role-holder, for the purposes of the formalisation it is convenient to restrict the properties that are ascribed directly to the role-holder to the latter set. Thus we will apply the predicate '... teaches Mathematics', say, to the role-holder John-as-Teacher1, but not to John himself, and we will apply the predicate '... has blue eyes' to John himself, but not to John-as-Teacher1.

This does not mean that we cannot say, for example, that a teacher has blue eyes, or that John teaches mathematics; the way we can do such things in our formalisation is illustrated by the following examples:

- Suppose John-as-Teacher1 runs the school Chess Club, but we want to say that John runs that club without explicit reference to his role as a teacher. We can write ${ }^{14}$

$$
\exists r, h(\operatorname{Holds}(j o h n, r, h, t) \wedge \operatorname{Runs}(h, \text { chess-club }, t)) .
$$

- Suppose John has blue eyes, and we want to say that Teacher1 has blue eyes. We write

$$
\exists x, r(\operatorname{Holds}(x, r, \text { teacher } 1, t) \wedge \operatorname{Blue-eyed}(x)) .
$$

\footnotetext{
${ }^{14}$ Here we use $t$ as a generic time-point - for rendering sentences in the present tense we can assume that $t$ denotes the present moment 'now'.
} 
- Suppose John sings bass in the local choir (nothing to do with the school), and we want to say that Teacher1 sings in the choir. Being a choir-member is, of course, itself a role, so we must write

$$
\exists x, r, r^{\prime}, h^{\prime}\left(\operatorname{Holds}(x, r, \text { teacher } 1, t) \wedge \operatorname{Holds}\left(x, r^{\prime}, h^{\prime}, t\right) \wedge \operatorname{Sings-bass}\left(h^{\prime}, t\right)\right) .
$$

We could, if we wished, include further details about the nature of the role $r^{\prime}$, for example, Context-of $\left(r^{\prime}, c\right)$, where $c$ denotes the particular choir in question, but the above formula already captures the essence of what we want to say.

The philosophy behind this approach is that the only properties we ascribe directly to a person are those properties which (s)he holds qua person, together with role ascriptions (the same idea applying, of course, to entities other than people). Other properties must be ascribed indirectly through the role ascriptions (for those properties which are possessed in a person's capacity as a role-holder) or similar devices (for properties belonging to phase sortals such as 'caterpillar' or 'baby').

An advantage of this approach is that it allows us, without contradiction, to ascribe contradictory properties to someone who possesses those properties as holders of different roles. Thus if John has separate roles as a mathematics teacher and as a geography teacher, and is popular with his pupils in the first role, but not in the second, then we can write

$$
\exists r, r^{\prime}, h, h^{\prime}\left(\text { Holds }(j o h n, r, h, t) \wedge \text { Holds }\left(j o h n, r^{\prime}, h^{\prime}, t\right) \wedge \operatorname{Popular}(h, t) \wedge \neg \operatorname{Popular}\left(h^{\prime}, t\right)\right) \text {. }
$$

We use the same approach for occurrent-dependent roles. Instead of Sings (rosemary, $t)$, for example, we write

$$
\exists r, h(\text { Holds (rosemary, } r, h, t) \wedge \operatorname{Sings}(h, t)),
$$

the role $r$ in this case being of type singer ${ }_{p r}$; and if Brutus murders Caesar, we write

$$
\exists r, h(\text { Holds(brutus, } r, h, t) \wedge \operatorname{Murders}(h, \text { caesar }, t)) .
$$

Here the role $r$ is of type murderer $_{e v}$. To say that Brutus, as Caesar's murderer, flees from Rome, we write

$$
\exists r, h(\text { Holds (brutus, } r, h, t) \wedge \text { Has-murdered }(h, \text { caesar }, t) \wedge \text { Flees }(h, \text { rome }, t)) .
$$

Here $t$ is a time at which Brutus flees Rome and at which it is true that he has murdered Caesar - not the time at which he murders Caesar. Thus the role $r$ in this formula is of retrospective type murderer $e_{e v}^{-}$. The connection between the retrospective role and the original role from which it is derived is expressed by

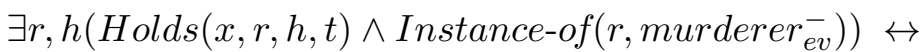

$$
\begin{aligned}
& \exists r^{\prime}, h^{\prime}, t^{\prime}\left(t^{\prime}<t \wedge \operatorname{Holds}\left(x, r^{\prime}, h^{\prime}, t^{\prime}\right) \wedge \text { Instance-of }\left(r^{\prime}, \text { murderer }_{e v}\right)\right)
\end{aligned}
$$

\subsection{Conclusion}

It must be emphasised that the formalisation is currently under development, so that what is presented in this section should be treated as provisional. We do not claim to have resolved all issues arising from the formalisation of our theory, but we believe it is important to include a preliminary formalisation here as a demonstration that the theory presented in the preceding parts of the paper can be placed on a precise and rigorous footing. Much remains to be done, however, and in particular we need to explore in detail the implications of incorporating our formalisation of roles within existing upper-level ontologies.

\section{Related Work}

Although roles have been discussed by many researchers (Boella, van der Torre, \& Verhagen,2007), very little appears to have been published concerning the main topics discussed in this paper. The existing literature on roles is scattered amongst a number of different areas of research, for example Ontology Engineering (Guarino,1992; Masolo et al.,2004;Loebe,2005,2007; Masolo et al.,2011), Database Modelling (Steimann,2000,2007), Software Engineering (Chernuchin \& Dittrich,2005;Baldoni, Boella, \& van 
der Torre,2005), and Agent Systems (Zambonelli, Jennings, \& Wooldridge,2003;Colman \& Han,2007). A computational model of roles together with their major characteristics was also discussed in our previous work (Mizoguchi et al.,2007), as summarised in Section 2.1.

Although some of these works enumerate features of roles, and a few authors have tried to find a proper definition of roles (Masolo et al.,2004;Steimann,2000), it remains an open question whether it is even possible to give a single definition of role which everyone can agree upon (Boella et al.,2007). This paper does not attempt to propose such a definition; instead, we simply aim to investigate the temporal aspects of roles and propose a new framework within which we can distinguish derived roles from original roles.

It is generally agreed that roles are dependent entities, but various ideas have been put forward as to precisely what they depend on. Steimann (2000) and Masolo et al. (2004) claim that roles depend on relations; Loebe (2007) claims that they depend on contexts. Most of the roles discussed by the authors are object-dependent roles such as teacher, whereas in this paper we have been mainly concerned with occurrent-dependent roles, with a focus on their temporal aspects.

Loebe (2007) discusses top-level categories based on the determination of roles by context. For Loebe, '[A] context is to be understood as a more comprehensive whole in which a role may be interpreted as a part. Indeed, assuming a very general notion of part-of, one can consider role-of as a specialisation of part-of.' Note that Loebe is here using role in the sense of our role-holder, and the 'very general' notion of part-of includes the participates-in relation between a continuant and an occurrent. He presents three role types: relational role, processual role, and social role, where his processual roles correspond to our original process-dependent roles. In many ways Loebe's approach is the closest to ours in terms of toplevel role organisation, but he does not discuss event-dependent roles, nor the family of occurrent roles comprising original and derived roles which is the main theme of our paper.

Fan, Barker, Porter, and Clark (2001) also recognises the importance of constructing a hierarchy of role concepts, and gives an example of Thing sub-classified into Entity and Role. Although the classification of roles is not the main topic of the present paper, our theory does provide a deeper hierarchy of roles than those presented by other authors. ${ }^{15}$ A main focus of (Fan et al.,2001) is to explore the relationship between roles and purposes. The authors distinguish two relations between roles and entities: played-by and purpose, where the former 'represents that an entity is actually participating in an event' and the latter 'represents a role that the entity is intended to play, but says nothing about whether it is actually doing so'. As an example they consider a hammer, whose purpose is 'to be the instrument of a hammering event', the role being played when the hammer actually participates in such an event. This distinction seems to occupy a similar territory to our distinction between holding and performing a role, but it is not exactly the same distinction - in particular, for us, holding a role need not involve purpose, though it may do so in many cases; more generally we would say that holding a role carries implications about what the role-holder may be expected to do when performing the role, whether or not that can be ascribed to any purpose.

In a previous co-authored paper (Masolo et al.,2011), constraints on the definitions of specific roles, as well as various different kinds of roles, are discussed in a formal way, In particular, the main aim of that paper is to solve the well-known 'counting problem'. In the discussion of kinds of roles, the initial idea of a derived role was discussed, and then formalised as historical role, characterised as 'roles that are played because of the fact that some other role was played in the past' (p. 81). Examples discussed included murderer and Everest-climber; the salient characteristic of these properties is that, once acquired, they persist forever, even when their bearers are no longer present. The idea of a family of occurrent-dependent roles is, we believe, original to the present paper, although it is in harmony with the views expressed in the earlier paper, where it is stated that 'the derived roles of interest here are specified so that the time of playing of the derived role differs from the time of playing of the original one' (pp.80-81).

${ }^{15} \mathrm{An}$ informal classification of roles which includes still more categories is discussed in (Mizoguchi et al.,2012b). 


\section{Concluding Remarks}

In this paper we have recapitulated and refined the theory of roles previously presented in (Mizoguchi et al.,2007), and developed in detail an account of temporal aspects of occurrent-dependent roles previously hinted at in (Masolo et al.,2011). We have introduced the distinction between original and derived roles in order to explain the nature of historical roles. This led us naturally to the idea of a family of roles in which are collected together an original role together with its associated derived roles, which may be either retrospective or prospective. We also examined a number of problem cases, showing how they may be handled within this framework; in particular, we noted that care is needed in applying these distinctions in particular cases, particularly where what may at first sight appear to be an occurrent-dependent role turns out, on deeper analysis, to be better handled as an object-dependent role (see in particular §5.3 and §5.4).

The family of occurrent-dependent roles helps us to identify what is ontologically primary, and what secondary, amongst similar roles. Moreover, by attending closely to the characteristics of these different kinds of roles we have been led to formulate a distinction between holding a role and performing it, which we believe has not previously been given sufficient attention.

Although we have proposed several new concepts which help to clarify some puzzling features of roles, many open questions remain. In particular, further work is needed to establish well-founded principles for addressing such issues as:

- When should a role be classified as occurrent-dependent and when as object-dependent? (Compare $\S 5.3$.

- How can habitual roles, which seem to be dependent on a continuant that is itself dependent on occurrent, be fully integrated into the theory? (See \$5.4.)

- How exactly should prospective derived roles be formalised, given that their contexts might never actually be present? (See §6.3.)

- What account should be given of roles played by occurrents? It is generally assumed that, whatever they are, roles are played by continuant entities, which may play their roles contingently and temporarily. But this is problematic if the entity playing the role is an occurrent. If someone washes their hands in preparation for eating, then the washing might be said to play the role of a pre-process; but when they wash their hands after eating, the washing, which may be qualitatively identical as an action, plays the different role of a post-process. None the less, these are numerically distinct actions, and it does not make sense to say that either of them assumes its role as a temporary part of its lifetime as one would when a continuant plays a role.

- Do object-dependent roles have derived roles too? What account should we give of roles such as ex-wife or president-elect, which look as though they might be described as retrospective and prospective derivatives from the object-dependent roles wife $e_{o b}$ and president $_{o b}$ respectively?

- How far is it possible to disentangle the specifically ontological aspects of roles from issues relating to the expression of roles in natural language? How important is it to do so? (See the discussion at the end of $\S 5.5$.)

These questions should be enough to convince the reader that the ontology of roles remains a live area of research in which there are still plenty of important results to be discovered. We offer this paper as a contribution to the ongoing debate, providing some pointers to important new topics for further development.

\section{Acknowledgments}

The authors are grateful to Nicola Guarino, Laure Vieu, Claudio Masolo, and Robert Rovetto for their comments, and also to Gilles Kassel, Paolo Terenziani, and Antonio Lieto, the official reviewers, whose comments were of great benefit to us in revising the paper. Material in this paper is partly based on research sponsored by the Air Force Research Laboratory under agreement number FA2386-13-1-4047. The U.S. Government is authorised to reproduce and distribute reprints for governmental purposes notwithstanding any copyright notation thereon. 


\section{Disclaimer}

The views and conclusions contained herein are those of the authors and should not be interpreted as necessarily representing the official policies or endorsements, either expressed or implied, of the Air Force Research Laboratory or the U.S. Government.

\section{References}

Baldoni, M., Boella, G., \& van der Torre, L. (2005). Introducing ontologically founded roles in objectoriented programming: powerJava. In G. Boella, L. van der Torre, \& H. Verhagen (Eds.), (p. 5-12). Arlington, Virginia: AAAI Technical Report FS-05-08.

Boella, G., van der Torre, L., \& Verhagen, H. (Eds.). (2005). Proceedings of the 2005 aaai fall symposium: Roles, an interdisciplinary perspective: Ontologies, languages, and multiagent systems. Arlington, Virginia: AAAI Technical Report FS-05-08.

Boella, G., van der Torre, L., \& Verhagen, H. (2007). Roles, an interdisciplinary perspective. Applied Ontology, 2, 81-88.

Chernuchin, D., \& Dittrich, G. (2005). Role types and their dependencies as components of natural types. In G. Boella, L. van der Torre, \& H. Verhagen (Eds.), (p. 49-46). Arlington, Virginia: AAAI Technical Report FS-05-08.

Colman, A., \& Han, J. (2007). Roles, players and adaptable organizations. Applied Ontology, 2, 105-126.

Davidson, D. (1969). The individuation of events. In N. Rescher (Ed.), Essays in honor of carl g. hempel. Dordrecht: D. Reidel. (Reprinted in D. Davidson, Essays on Actions and Events, Oxford, Clarendon Press, 1980, pages 163-80)

Fan, J., Barker, K., Porter, B., \& Clark, P. (2001). Representing roles and purpose. In Y. Gil, M. Musen, \& J. Shavlik (Eds.), Proceedings of the first international conference on knowledge capture, victoria, canada, oct 21-23, 2001 (p. 38-43). New York: Association for Computing Machinery.

Galton, A. P., \& Mizoguchi, R. (2009). The water falls but the waterfall does not fall: New perspectives on objects, processes and events. Applied Ontology, 4(2), 71-107.

Guarino, N. (1992). Concepts, attributes and arbitrary relations. Data \& Knowledge Engineering, 8, 249-261.

Guizzardi, G. (2005). Ontological foundations for structural conceptual models. University of Twente, The Netherlands: Centre for Telematics and Information Technology. ( $\mathrm{PhD}$ thesis)

Guizzardi, G. (2006). Agent roles, qua individuals and the counting problem. In A. Garcia, R. Choren, C. Lucena, P. Giorgini, T. Holvoet, \& A. Romanovsky (Eds.), Software engineering for multi-agent systems iv: Research issues and practical applications (Vol. 3914, p. 143-163). Berlin: Springer.

Kozaki, K., Kitamura, Y., \& Mizoguchi, R. (2012). A model of derived roles. In A. ten Teije \& et al (Eds.), Knowledge engineering and knowledge management, proceedings of ekaw 2012, galway city, ireland (p. 227-236). Berlin and Heidelberg: Springer.

Loebe, F. (2005). Abstract vs social roles: A refined top-level ontological analysis. In G. Boella, L. van der Torre, \& H. Verhagen (Eds.), (p. 93-100). Arlington, Virginia: AAAI Technical Report FS-05-08.

Loebe, F. (2007). Abstract vs social roles: Towards a general theoretical account of roles. Applied Ontology, 2, 127-158.

Masolo, C., Guizzardi, G., Vieu, L. R., Bottazzi, E., \& Ferrario, R. (2005). Relational roles and quaindividuals. In G. Boella, J. Odell, L. van der Torre, \& H. Verhagen (Eds.), Proceedings of the aaai symposium on roles, an interdisciplinary perspective (p. 103-112). Arlington, Virginia: AAAI Press.

Masolo, C., Vieu, L., Bottazzi, E., Catenacci, C., Ferrario, R., Gangemi, A., \& Guarino, N. (2004). Social roles and their descriptions. In D. Dubois, C. Welty, \& M.-A. Williams (Eds.), Principles of knowledge representation and reasoning, proceedings of the ninth international conference (kr2004), whistler bc, canada, june 2-5, 2004 (p. 267-277). Menlo Park, California: AAAI Press. 
Masolo, C., Vieu, L., Kitamura, Y., Kozaki, K., \& Mizoguchi, R. (2011). The counting problem in the light of role kinds. In E. Davis, P. Doherty, \& E. Erdem (Eds.), Commonsense 2011: Proceedings of the tenth international symposium on logical formalization on commonsense reasoning (stanford, usa, 21-23 march 2011) (chap. 24). AAAI Press.

Mizoguchi, R., Kozaki, K., \& Kitamura, Y. (2012a). Ontological analyses of roles. In Proceedings of the federated conference on computer science and information systems, wroctav, poland, 9th-12th september 2012 (p. 489-496). IEEE.

Mizoguchi, R., Kozaki, K., \& Kitamura, Y. (2012b). A taxonomy of roles. In M. Okada \& B. Smith (Eds.), Interdisciplinary ontology: Proceedings of the fifth interdisciplinary ontology meeting, febraury 23rd-24th, 2012 (p. 117-122). Keio University, Tokyo, Japan: Open Research Centre for Logic and Ontology.

Mizoguchi, R., Sunagawa, E., Kozaki, K., \& Kitamura, Y. (2007). The model of roles within an ontology development tool: Hozo. Applied Ontology, 2, 159-179.

Moens, M., \& Steedman, M. (1988). Temporal ontology and temporal reference. Computational Linguistics, 14, 15-28. (Reprinted in Mani, I., Pustejovsky J., and Gaizauskas, R., The Language of Time: A Reader, Oxford, 2005)

Pols, A. J. K. (2013). Choosing your poison and the time of a killing. Philosophical Studies, 165, 719-733.

Steimann, F. (2000). On the representation of roles in object-oriented and conceptual modelling. Data \& Knowledge Engineering, 35, 83-106.

Steimann, F. (2007). The role data model revisited. Applied Ontology, 2, 89-103.

Thomson, J. J. (1971). The time of a killing. Journal of Philosophy, 68, 115-132.

Zambonelli, F., Jennings, N. R., \& Wooldridge, M. (2003). Developing multiagent systems: The Gaia methodology. ACM Transactions on Software Engineering and Methodology, 12(3), 317-370. 